\title{
OPEN Heat dissipation in subterranean rodents: the role of body region and social organisation
}

\author{
František Vejmělka ${ }^{1}$, Jan Okrouhlík ${ }^{1,2}$, Matěj Lövy ${ }^{1}$, Gabriel Šaffa ${ }^{1}$, Eviatar Nevo ${ }^{3}$, \\ Nigel Charles Bennett ${ }^{2}$ \& Radim Šumbera ${ }^{1 凶}$
}

The relatively warm and very humid environment of burrows presents a challenge for thermoregulation of its mammalian inhabitants. It was found that African mole-rats dissipate body heat mainly through their venter, and social mole-rats dissipate more body heat compared to solitary species at lower temperatures. In addition, the pattern of the ventral surface temperature was suggested to be homogeneous in social mole-rats compared to a heterogeneous pattern in solitary mole-rats. To investigate this for subterranean rodents generally, we measured the surface temperatures of seven species with different degrees of sociality, phylogeny, and climate using infrared thermography. In all species, heat dissipation occurred mainly through the venter and the feet. Whereas the feet dissipated body heat at higher ambient temperatures and conserved it at lower ambient temperatures, the ventral surface temperature was relatively high in all temperatures indicating that heat dissipation to the environment through this body region is regulated mainly by behavioural means. Solitary species dissipated less heat through their dorsum than social species, and a tendency for this pattern was observed for the venter. The pattern of heterogeneity of surface temperature through the venter was not related to sociality of the various species. Our results demonstrate a general pattern of body heat exchange through the three studied body regions in subterranean rodents. Besides, isolated individuals of social species are less able to defend themselves against low ambient temperatures, which may handicap them if staying alone for a longer period, such as during and after dispersal events.

The heat exchange between an endotherm and its environment is mediated via radiation, conduction, convection, and evaporation (e.g. ${ }^{1}$ ). In mammals, the transfer of excess heat to the environment is facilitated by socalled thermal windows. These sparsely furred body regions are usually found at the body extremities, e.g. ear pinnae $e^{2,3}$, the feet ${ }^{3-6}$, and the tail ${ }^{7}$, but may also occur on the trunk ${ }^{8}$, and on the ventral body side ${ }^{9-13}$. Together with behavioural regulation, such as posture changes, or seeking convenient microhabitats, heat transfer in these body parts is regulated mainly by vasodilatation and vasoconstriction ${ }^{1}$.

Mammalian thermal biology is influenced by multiple factors, but body size plays a crucial role. Compared to their larger counterparts, small mammals have to compensate for the relatively higher heat losses in cold environments due to their larger surface-to-volume ratio ${ }^{14}$. There are various strategies as to how small mammals can minimise heat loss at low ambient temperature $\left(\mathrm{T}_{\mathrm{a}}\right)$. For example, an individual curled up into a ball reduces its surface-to-volume ratio ${ }^{15-17}$. Similarly, huddling as a mechanism of social thermoregulation decreases heat loss rate $\left(\right.$ e.g. $\left.{ }^{18-20}\right)$. At higher $\mathrm{T}_{\mathrm{a}} \mathrm{s}$, rapid heat dissipation is crucial, especially in situations where animals produce a surplus of metabolic heat, for example due to heavy physical activity. Animals move to a place with a more suitable microclimate or increase their evaporative water loss by sweating and/or panting. Thermal windows may also be actively exposed to the environment at high $\mathrm{T}_{\mathrm{a}} \mathrm{s}^{12,21}$.

Mammals living in subterranean burrows face a very challenging environment including difficulties in heat dissipation. The burrow environment is relatively warm and very humid ( $>80 \%$ relative humidity even in very arid areas) with limited ventilation, and such a combination presents a problem for their thermoregulation ${ }^{22-25}$. In addition, excavation of burrows, which is the main way to reach food, increases metabolic rate up to five times that of resting $22,26-28$. Thus, the surplus body heat related to such increase needs to be effectively dissipated to

${ }^{1}$ Department of Zoology, Faculty of Science, University of South Bohemia, 37005 České Budějovice, Czech Republic. ${ }^{2}$ Department of Zoology and Entomology, Mammal Research Institute, University of Pretoria, Pretoria 0002, South Africa. ${ }^{3}$ Institute of Evolution, University of Haifa, 3498838 Haifa, Israel. ${ }^{\varpi}$ email: sumbera@ prf.jcu.cz 
avoid overheating ${ }^{22,29}$. Although subterranean mammals live in a thermally relatively stable environment whose overall $\mathrm{T}_{\mathrm{a}}$ does not decrease much below the thermoneutral zone (TNZ), most of them have dense fur that well conserve body heat ${ }^{30-33}$. This may complicate heat offloading at higher $\mathrm{T}_{\mathrm{a}} \mathrm{s}$ or after digging. Finally, these mammals have reduced or even lack most body extremities such as tails and ear pinnae used for heat dissipation in non-fossorial mammals.

From this point of view it has for a long time been an enigma as to how subterranean mammals avoid overheating, especially during highly heat-producing activities. It was speculated that the excess metabolic heat is dissipated mainly through the venter in the Talas tuco-tuco Ctenomys talarum ${ }^{34}$. This heat dissipation pathway was later supported by the analysis of surface temperatures $\left(T_{s}\right)$, i.e. temperature of the fur surface facing to the environment, in five African mole-rats (Bathyergidae, Rodentia) ${ }^{31,35}$. Both studies demonstrated that the feet which are generally less haired compared to other body regions in all bathyergids also play a relevant role in heat dissipation. It was also shown that two mole-rat species, the giant mole-rat Fukomys mechowii and the silvery mole-rat Heliophobius argenteocinereus, cool themselves very effectively, while burrowing via contact of their body with the colder surrounding soil, especially when the soil is wet ${ }^{36}$. Although interspecific differences in heat dissipation in mole-rats could be attributed mainly to the climate of the habitats ${ }^{35}$, remarkable differences were found, surprisingly, also between species from the same climatic conditions and habitats. Thus, social F. mechowii has a shorter and sparser fur allowing more effective body heat dissipation and thus higher $\mathrm{T}_{\mathrm{s}}$ compared to the solitary $H$. argenteocinereus which has longer and denser fur across most of its body ${ }^{31}$. Higher heat dissipation for social species is disadvantageous at lower $\mathrm{T}_{\mathrm{a}} \mathrm{s}$, but is reduced by huddling ${ }^{37,38}$. Both species also differed in the pattern of $\mathrm{T}_{\mathrm{s}}$ on the venter. Whereas $F$. mechowii had a uniformly high $\mathrm{T}_{\mathrm{s}}$ distributed across its venter, $H$. argenteocinereus had a smaller area of high $\mathrm{T}_{\mathrm{s}}$ on the chest, and the rest of the ventral surface was remarkably colder making the venter heterogeneous in terms of $\mathrm{T}_{\mathrm{s}}{ }^{31}$. However, interpretations regarding the heterogeneity of thermal windows related to differences in social organisation are preliminary because only one solitary and one social species have been compared so far (cf. $\left.{ }^{31}\right)$.

Apart from fur, heat dissipation through a particular body region could be influenced by the characteristics of skin and fat tissue as exhibited in aquatic mammals ${ }^{39}$, or small terrestrial mammals ${ }^{40}$. Nevertheless, to be able to move easily through burrows, mole-rats and probably also other subterranean mammals do not store fat as a subcutaneous layer ${ }^{41,42}$. A recent analysis did not show any remarkable differences in parameters of skin and fat tissue between the dorsum and venter in F. mechowii which supports an exclusive role of fur in heat dissipation through the integument ${ }^{43}$. Different fur characteristics can thus have relevant behavioural and ecological consequences in subterranean rodents. For example, it has been suggested that well insulating fur allows H. argenteocinereus to colonise the highest altitudes of the Nyika Plateau in Malawi, whereas the sympatric social Whyte's mole-rat Fukomys whytei occurs at lower altitudes ${ }^{44}$. We may predict that individuals of social species, when dispersing singly, have higher thermoregulatory costs due to a less insulating fur because they cannot decrease heat losses by huddling, one of the most efficient energy saving mechanisms in small social mammals ${ }^{20}$. Although it is very difficult to obtain data on the duration of staying alone in social subterranean species in nature, several records indicate solitary individuals of social mole-rats stay for weeks, months or even years on their own ${ }^{45-48}$.

In the current study, we recorded $\mathrm{T}_{\mathrm{s}}$ using infrared thermography (IRT), and core body temperature $\left(\mathrm{T}_{\mathrm{b}}\right)$ to analyse heat dissipation ability, the presence of thermal windows, and the role of social organisation in seven species of subterranean rodents over a $\mathrm{T}_{\mathrm{a}}$ gradient from 10 to $35^{\circ} \mathrm{C}$. The studied species originated from different phylogenetic lineages (families Bathyergidae, Octodontidae, Spalacidae), climatic zones, and continents with representatives from both social and solitary species (for details see Table 1 ). As $\mathrm{T}_{\mathrm{b}}$ may differ among the tested species, we introduce $T_{\text {diff }}$ parameter defined as the difference between $T_{b}$ and $T_{s}$ of a particular body region (the dorsum, venter, and feet) at each $\mathrm{T}_{\mathrm{a}}$ to quantify heat dissipation. Higher values of this parameter indicate lower heat dissipation from the respective body region to its surrounding. Since $\mathrm{T}_{\text {diff }}$ is determined mainly by the value of $T_{s}$, while $T_{b}$ changes much less, we did not test $T_{s}$ in most analyses to avoid redundant results similar to those of $\mathrm{T}_{\text {diff. }}$. We focused mainly on both extreme $\mathrm{T}_{\mathrm{a}} \mathrm{s}\left(10\right.$ and $\left.35^{\circ} \mathrm{C}\right)$, and a $\mathrm{T}_{\mathrm{a}}$ within $\mathrm{TNZ}$ of all species $\left(30^{\circ} \mathrm{C}\right)$. We hypothesized that:

(a) Smaller $\mathrm{T}_{\text {diff }}$ will be found on the venter compared with the dorsum and feet at lower $\mathrm{T}_{\mathrm{a}} \mathrm{s}$ confirming the existence of the ventral heat dissipation surface in all species. At these low $\mathrm{T}_{a} \mathrm{~s}$, larger $\mathrm{T}_{\mathrm{diff}}$ on the feet and dorsum is a consequence of vasoconstriction in the feet, and better fur insulation of the dorsum. Furthermore, $\mathrm{T}_{\text {diff }}$ will be smaller in all three body regions at the highest $\mathrm{T}_{\mathrm{a}} \mathrm{s}$ when body heat needs to be dissipated at the highest possible rate from all body surfaces to avoid overheating.

(b) $\mathrm{T}_{\text {diff }}$ will be generally smaller on the venter and dorsum in social compared to solitary species indicating easier heat dissipation through these regions in social species. No differences in $\mathrm{T}_{\text {diff }}$ are expected for the feet because they are less haired in both solitary and social species.

(c) The pattern of $\mathrm{T}_{\text {diff }}$ along the ventral body region will be homogeneous in social species, and heterogeneous in solitary species. The heterogeneity in $\mathrm{T}_{\text {diff }}$ in solitary species will be caused by smaller $\mathrm{T}_{\text {diff }}$ on the less furred chest compared to higher $\mathrm{T}_{\text {diff }}$ of other areas of the venter. Next, the venter will be homogeneous in $\mathrm{T}_{\text {diff }}$ in all species at highest $\mathrm{T}_{\mathrm{a}} \mathrm{s}$, when body heat needs to be dissipated by the whole ventral surface to avoid overheating.

\section{Material and methods}

Tested animals. Altogether 73 individuals from seven species of subterranean rodents differing in body mass, phylogenetic relatedness, and sociality were studied (Table 1). All animals were adult non-breeders, or their breeding history was unknown in solitary species, but none of them showed signs of recent breeding, which may theoretically influence measured parameters. For the purpose of this study, we used the following taxa. 


\begin{tabular}{|c|c|c|c|c|c|c|c|c|c|c|c|}
\hline Species (n) & $\begin{array}{l}\text { Social } \\
\text { organisation }\end{array}$ & $\begin{array}{l}\text { Body mass } \\
\text { (g) }\end{array}$ & $\operatorname{TNZ}\left({ }^{\circ} \mathrm{C}\right)$ & \begin{tabular}{|l|} 
Burrow \\
temperature \\
$\left({ }^{\circ} \mathrm{C}\right)$
\end{tabular} & $\begin{array}{l}\text { Altitude (m } \\
\text { a.s.l.) }\end{array}$ & $\begin{array}{l}\text { Locality } \\
\text { (GPS) }\end{array}$ & Climatic zone & AP $(\mathbf{m m})$ & AMT $\left({ }^{\circ} \mathrm{C}\right)$ & MT $\left({ }^{\circ} \mathrm{C}\right)$ & $\operatorname{TAR}\left({ }^{\circ} \mathrm{C}\right)$ \\
\hline B. suillus (10) & Solitary & $694 \pm 146$ & $25-31^{50}$ & $12.4-31.6^{\mathrm{a}}$ & 252 & $\begin{array}{l}\text { Darling, R. of } \\
\text { South Africa } \\
\left(33^{\circ} 22^{\prime} \mathrm{S}, 18^{\circ}\right. \\
\left.25^{\prime} \mathrm{E}\right)\end{array}$ & Subtropics & 435 & 17.6 & 6.7 & 20.8 \\
\hline G. capensis (9) & Solitary & $148 \pm 48$ & $26.3-34^{42}$ & $\begin{array}{l}12.0-30.7^{\mathrm{a}} \\
9.8-36.3^{\mathrm{b}} \\
10.2-29.7^{55}\end{array}$ & 252 & $\begin{array}{l}\text { Darling, R. of } \\
\text { South Africa } \\
\left(33^{\circ} 22^{\prime} \mathrm{S}, 18^{\circ}\right. \\
\left.25^{\prime} \mathrm{E}\right)\end{array}$ & Subtropics & 435 & 17.6 & 6.7 & 20.8 \\
\hline $\begin{array}{l}\text { C. hottentotus } \\
\text { (10) }\end{array}$ & Social & $71 \pm 13$ & $27-30^{51}$ & $15.9-27.8^{55}$ & 252 & $\begin{array}{l}\text { Darling, R. of } \\
\text { South Africa } \\
\left(33^{\circ} 22^{\prime} \mathrm{S}, 18^{\circ}\right. \\
\left.25^{\prime} \mathrm{E}\right) \\
\end{array}$ & Subtropics & 435 & 17.6 & 6.7 & 20.8 \\
\hline F. anselli (9) & Social & $80 \pm 11$ & $26-30^{53}$ & $18-26^{56 e}$ & 1320 & $\begin{array}{l}\text { Lusaka, Zam- } \\
\text { bia }\left(15^{\circ} 28^{\prime} \mathrm{S},\right. \\
\left.28^{\circ} 25^{\prime} \mathrm{E}\right)\end{array}$ & Tropics & 824 & 19.9 & 7.7 & 22.2 \\
\hline $\begin{array}{l}F \text {. "Nsanje" } \\
\text { (10) }\end{array}$ & Social & $139 \pm 27$ & $27-34^{52}$ & - & 53 & \begin{tabular}{|l|} 
Nsanje, \\
Malawi $\left(16^{\circ}\right.$ \\
$55^{\prime} \mathrm{S}, 35^{\circ}$ \\
$\left.16^{\prime} \mathrm{E}\right)$ \\
\end{tabular} & Tropics & 842 & 25.7 & 14 & 21.8 \\
\hline S. cyanus (5) & Social & $101 \pm 19$ & $26-33^{5}$ & $8-32.1^{57}$ & Not known & $\begin{array}{l}\text { Not known, } \\
\text { Chile }\end{array}$ & $\begin{array}{l}\text { Subtropics/ } \\
\text { temperate }\end{array}$ & 377 & 13.1 & 1.9 & 22.0 \\
\hline N. galili (20) & Solitary & $171 \pm 32$ & $26.4-(>33)^{83, \mathrm{~d}}$ & $5.4-34.6^{c}$ & 770 & $\begin{array}{l}\text { Gush Halav, } \\
\text { Israel }\left(33^{\circ} 02^{\prime}\right. \\
\left.\mathrm{N}, 35^{\circ} 27^{\prime} \mathrm{E}\right)\end{array}$ & Subtropics & 791 & 16.7 & 1.3 & 28.2 \\
\hline
\end{tabular}

Table 1. Characteristics of seven studied species of subterranean rodents and their habitats. Means \pm SD of body masses are given. Numbers in parentheses after the species names represent sample sizes. TNZ, thermoneutral zone; AP, annual precipitation; AMT, annual mean temperature; MT, minimal temperature; TAR, temperature annual range (climatic parameters were downloaded from the Worldclim database ${ }^{49}$; due to the unknown locality of S. cyanus, climatic data from the whole species range were used). 'J. Okrouhlík, unpublished data, soil temperature $30 \mathrm{~cm}$ deep, yearly range in 2017/2018, measured every hour. ${ }^{b} J$. Okrouhlík, unpublished data, soil temperature $10 \mathrm{~cm}$ deep, yearly range in 2017/2018, measured every hour. ${ }^{\mathrm{c}} \mathrm{M}$. Lövy, unpublished data, soil temperature $20 \mathrm{~cm}$ deep, yearly range in $2014 / 2015$, measured every $15 \mathrm{~min}$. ${ }^{\mathrm{d}}$ Upper limit is not known, but our unpublished data indicate that it is above $33{ }^{\circ} \mathrm{C}$ in N. galili. ${ }^{e}$ Winter season.

African mole-rats (Bathyergidae): the social Ansell's mole-rat Fukomys anselli (Burda, Zima, Scharff, Macholán \& Kawalika 1999) occupies the miombo in a small area near Zambia's capital Lusaka; another social species of the genus Fukomys is named here as Fukomys "Nsanje" because founders of the breeding colony were captured near town Nsanje in south Malawi. Although we used name Fukomys darlingi (Thomas 1895) for mole-rats from this population in previous studies (e.g. ${ }^{38,49}$ ), its taxonomic status is still not resolved; the social common molerat Cryptomys hottentotus hottentotus (Lesson, 1826) occurs in mesic and semi-arid regions of southern Africa; the solitary Cape dune mole-rat Bathyergus suillus (Schreber, 1782) inhabits sandy soils along the south-western coast of South Africa; and the solitary Cape mole-rat Georychus capensis (Pallas, 1778) occupies mesic areas of the South Africa ${ }^{50}$. In addition, we studied the social coruro Spalacopus cyanus (Molina, 1782) (Octodontidae) occupying various habitats in Chile ${ }^{51}$; and the solitary Upper Galilee Mountains blind mole rat Nannospalax galili (Nevo, Ivanitskaya \& Beiles 2001) (Spalacidae) from Israel ${ }^{52}$. Further information about the species including number of individuals used in the study, their physiology and ecology is shown in Table 1.

All experiments were done on captive animals. Georychus capensis, C. hottentotus, and B. suillus, were captured about four months before the experiment, and kept in the animal facility at the University of Pretoria, South Africa (temperature: $23^{\circ} \mathrm{C}$; humidity: $40-60 \%$, photoperiod: 12L:12D). The animals were housed in plastic boxes with wood shavings used as a bedding. Cryptomys hottentotus and G. capensis were fed with sweet potatoes; $B$. suillus with sweet potatoes, carrots, and fresh grass. Fukomys anselli, F. "Nsanje", N. galili, and S. cyanus were kept for at least three years in captivity (or born in captivity) before the experiment in the animal facility at the University of South Bohemia in České Budějovice, Czech Republic (temperature: African mole-rats $25^{\circ} \mathrm{C}, \mathrm{N}$. galili and S. cyanus $23^{\circ} \mathrm{C}$; humidity: $40-50 \%$, photoperiod: $12 \mathrm{~L}: 12 \mathrm{D}$ ). The animals were kept in terraria with peat as a substrate and fed with carrots, potatoes, sweet potatoes, beetroot, apple, and rodent dry food mix ad libitum.

Experimental design. We measured $\mathrm{T}_{\mathrm{b}}$ and $\mathrm{T}_{\mathrm{s}}$ in all species at six $\mathrm{T}_{\mathrm{a}} \mathrm{s}\left(10,15,20,25,30\right.$ and $\left.35^{\circ} \mathrm{C}\right)$. Each individual of all species was measured only once in each $\mathrm{T}_{\mathrm{a}}$. Measurements were conducted in temperature controlled experimental rooms in České Budějovice and Pretoria. Each animal was tested on two experimental days.

The animals were placed in the experimental room individually in plastic buckets with wood shavings as bedding. On the first day, the experimental procedure started at $\mathrm{T}_{\mathrm{a}} 25^{\circ} \mathrm{C}$. They spent $60 \mathrm{~min}$ of initial habituation in the first $\mathrm{T}_{\mathrm{a}}$ after which $\mathrm{T}_{\mathrm{b}}$ and $\mathrm{T}_{\mathrm{s}}$ were measured as described in the following paragraphs. The $\mathrm{T}_{\mathrm{a}}$ was then increased to $30^{\circ} \mathrm{C}$ and $35^{\circ} \mathrm{C}$, respectively. After the experimental room reached the focal $\mathrm{T}_{\mathrm{a}}$, the animals were left minimally $30 \mathrm{~min}$ in each $\mathrm{T}_{\mathrm{a}}$ to acclimate, and the measurements were repeated. Considering their relatively small body size, tested animals were very likely in thermal equilibrium after this period because mammals of a 
comparable body mass are thermally equilibrated after similar period of acclimation ${ }^{53-56}$. On the second day, the procedure was repeated with the initial $\mathrm{T}_{\mathrm{a}} 20^{\circ} \mathrm{C}$ and decreasing to $15^{\circ} \mathrm{C}$ and $10{ }^{\circ} \mathrm{C}$, respectively. The time span between the measurements of the same individual in different $\mathrm{T}_{\mathrm{a}}$ was at least $150 \mathrm{~min}$. Between experimental days, the animals were kept at $25^{\circ} \mathrm{C}$ in the experimental room (individuals of social species were housed together with their family members).

Body temperature measurements. We used two sets of equipment to measure animal $\mathrm{T}_{\mathrm{b}}$ and $\mathrm{T}_{\mathrm{s}}$. In $B$. suillus, G. capensis, and C. hottentotus, $\mathrm{T}_{\mathrm{b}}$ was measured by intraperitoneally injected PIT tags $(<1 \mathrm{~g}$, LifeChip with Bio-Thermo Technology; Destron Fearing Corp., Dallas, Texas, USA, accuracy $0.5^{\circ} \mathrm{C}$, resolution $\left.0.1{ }^{\circ} \mathrm{C}\right)$. A vet injected the tags under anaesthesia (Isoflurane) three months before the experiment. The tags were calibrated by the manufacturer and were read using a Global Pocker Reader EX (Destron Fearing Corp., Dallas, Texas, USA). $\mathrm{T}_{\mathrm{s}}$ was measured by FLIR SC325 thermal camera (FLIR Systems, Inc., Wilsonwille, Oregon, USA; sensitivity $<50 \mathrm{mK}$, accuracy $\pm 2 \%$, frame rate $31 \mathrm{fps}$, calibrated by the manufacturer).

Core body temperatures of F. "Nsanje", F. anselli, N. galili, and S. cyanus were measured using a RET-2 temperature probe (Physitemp Instruments LLC., Clifton, New Jersey, USA; tip diameter $3.2 \mathrm{~mm}$, inserted at least $2 \mathrm{~cm}$ in the rectum, accuracy $0.1^{\circ} \mathrm{C}$ ) connected to Thermalert TH-8 (Physitemp Instruments LLC., Clifton, New Jersey, USA; resolution $0.1^{\circ} \mathrm{C}$ ). This procedure took less than $30 \mathrm{~s}$. The apparatus was verified against a thermometer (EL-USB-2-LCD+; Lascar Electronics Ltd., Salisbury, UK; overall accuracy $0.45^{\circ} \mathrm{C}$ ) calibrated by an accredited laboratory. Both means of measuring $\mathrm{T}_{\mathrm{b}}$ have been shown to provide almost identical results in small mammals including one species belonging to African mole-rats ${ }^{57-59}$. Surface temperature was measured using a Workswell WIRIS thermal imaging system (ver. 1.5.0, Workswell s.r.o., Praha, Czech Republic, sensitivity 30 $\mathrm{mK}$, accuracy $\pm 2 \%$, frame rate $9 \mathrm{fps}$, calibrated by the manufacturer). Both thermal cameras were calibrated prior to measurement of each animal, and we used the same software to process the raw thermograms (see below).

To measure $\mathrm{T}_{\mathrm{s}}$, a focused radiometric video of the animal was taken with its different body parts exposed perpendicularly to the camera. More specifically, the animals were held hanging by the loose skin around the tail, and their dorsal and ventral body regions were sequentially exposed to the camera. This procedure took less than $30 \mathrm{~s}$. To ensure unbiased $\mathrm{T}_{\mathrm{s}}$ measurements, all fans in the experimental room were switched off during measurements, and a non-uniformity correction (type of calibration of the camera) was performed just before measuring each animal. Since the seven tested species were of different sizes, and the lenses of the two thermal cameras had different focal lengths, and thus field of views, the animals were filmed at different distances from the camera to fully utilise the resolution of the two cameras. Distances of animals to the camera lens were $38-42 \mathrm{~cm}$ for $N$. galili, F. anselli, F. "Nsanje”, and S. cyanus, $53-57 \mathrm{~cm}$ for C. hottentotus, $64-68 \mathrm{~cm}$ for G. capensis, and $86-92 \mathrm{~cm}$ for B. suillus. Room air temperature and humidity were monitored throughout the trials (EL-USB-2-LCD+; Lascar Electronics Ltd., Salisbury, UK; calibrated by a certified laboratory). Humidity in both labs ranged from 47 to $72 \%$ during all experiments.

To assess the heat dissipation (which is related mainly to insulative properties of the integument) of each species regardless of their actual value of $T_{b}$, we introduced $T_{\text {diff }}$ parameter defined as the difference between $T_{b}$ and $\mathrm{T}_{\mathrm{s}}$ of a particular body region of each individual (the dorsum, the venter, and the feet) at each $\mathrm{T}_{\mathrm{a}}$.

Handling stress may influence $\mathrm{T}_{\mathrm{b}}$ and may also evoke vasoconstriction on the periphery and thus potentially affect $\mathrm{T}_{s}^{58}$. To test the potential influence of handling procedures employed in our study on $\mathrm{T}_{s}$ and $\mathrm{T}_{\mathrm{b}}$, we carried out several simple experiments. Firstly, we measured $\mathrm{T}_{\mathrm{b}}$ of three individuals of $F$. mechowii (species not included in the present study, but in ${ }^{31}$ ) by intraperitoneal probes (G2-HR E-Mitter, Starr Life Sciences Corp., Oakmont, Pennsylvania, USA; the only species with these probes in our breeds), and found no significant differences in $\mathrm{T}_{\mathrm{b}}$ prior to or after the $30 \mathrm{~s}$ handling period $\left(\mathrm{T}_{\mathrm{b}}\right.$ was $34.0 \pm 0.6^{\circ} \mathrm{C}$ and $34.1 \pm 0.7^{\circ} \mathrm{C}$ before and after handling, respectively; paired $\mathrm{t}$-test: $\mathrm{t}=-0.42, \mathrm{df}=3, p=0.70)$. Secondly, to exclude the possibility of a long-term effect of repeated handling on $\mathrm{T}_{\mathrm{b}}$, we simulated the measurement procedure with another three individuals of the same species with intraperitoneally injected PIT tags obtaining $\mathrm{T}_{b} \mathrm{~s}$ without direct contact. We placed mole-rats singly in a bucket and after $150 \mathrm{~min}$ we measured their $\mathrm{T}_{\mathrm{b}}$. Subsequently, we lifted them for a period of one min and returned them into the bucket. After $150 \mathrm{~min}$, we again measured their $\mathrm{T}_{\mathrm{b}} \mathrm{s}$. Lifting of the mole-rats and temperature measurement was repeated once again (Note that $150 \mathrm{~min}$ is the minimal period between two manipulations of each individual in our experiment). The $\mathrm{T}_{\mathrm{b}} \mathrm{s}$ did not change during these three subsequent measurements (Generalized Least Squares model [GLS]: $\mathrm{F}=0.7, p=0.544 ; \mathrm{T}_{\mathrm{b}}$ values were 33.14 $\pm 0.6,33.13 \pm 0.77$ and $33.23 \pm 0.92^{\circ} \mathrm{C}$ ). Thirdly, to rule out a possible effect of handling on $\mathrm{T}_{s}$, we measured dorsal $\mathrm{T}_{s}$ in ten individuals of $F$. "Nsanje" (species included in the present study) before and after the handling period which took usually less than $30 \mathrm{~s}$. Similarly, we did not find significant differences $\left(\mathrm{T}_{\mathrm{s}}\right.$ was $30.5 \pm 1.1^{\circ} \mathrm{C}$ and $30.3 \pm 1.1^{\circ} \mathrm{C}$ before and after the $30 \mathrm{~s}$ handling, respectively; paired t-test: $\mathrm{t}=1.78, d f=9, p=0.11)$. It should be noted that all animals are accustomed to this handling, as they undertake it on a weekly basis during routine activities, such as weighing, cleaning of terraria, and miscellaneous behavioural and physiological experiments. We therefore suggest that the different approaches in obtaining $\mathrm{T}_{\mathrm{b}}$, and different time in captivity for experimental animals did not affect our results substantially.

Thermogram processing and analysis. The thermographic camera produces (sequences of) images in the infrared range, so-called thermograms. Sharp and high contrast radiometric thermograms of the dorsum, the venter and one hind foot as a representative of the feet, were captured from the raw radiometric video in the software CorePlayer (ver. 1.7.70.320; Workswell s.r.o., Praha, Czech Republic; https://workswell-thermal-camer a.com/workswellcoreplayer), and processed into non-radiometric thermograms by specifying temperature calculation parameters in the software ThermoFormat (Workswell s.r.o., Praha, Czech Republic; https://workswellthermal-camera.com/workswell-thermoformat). These parameters were entered as follows: fur emittance was 


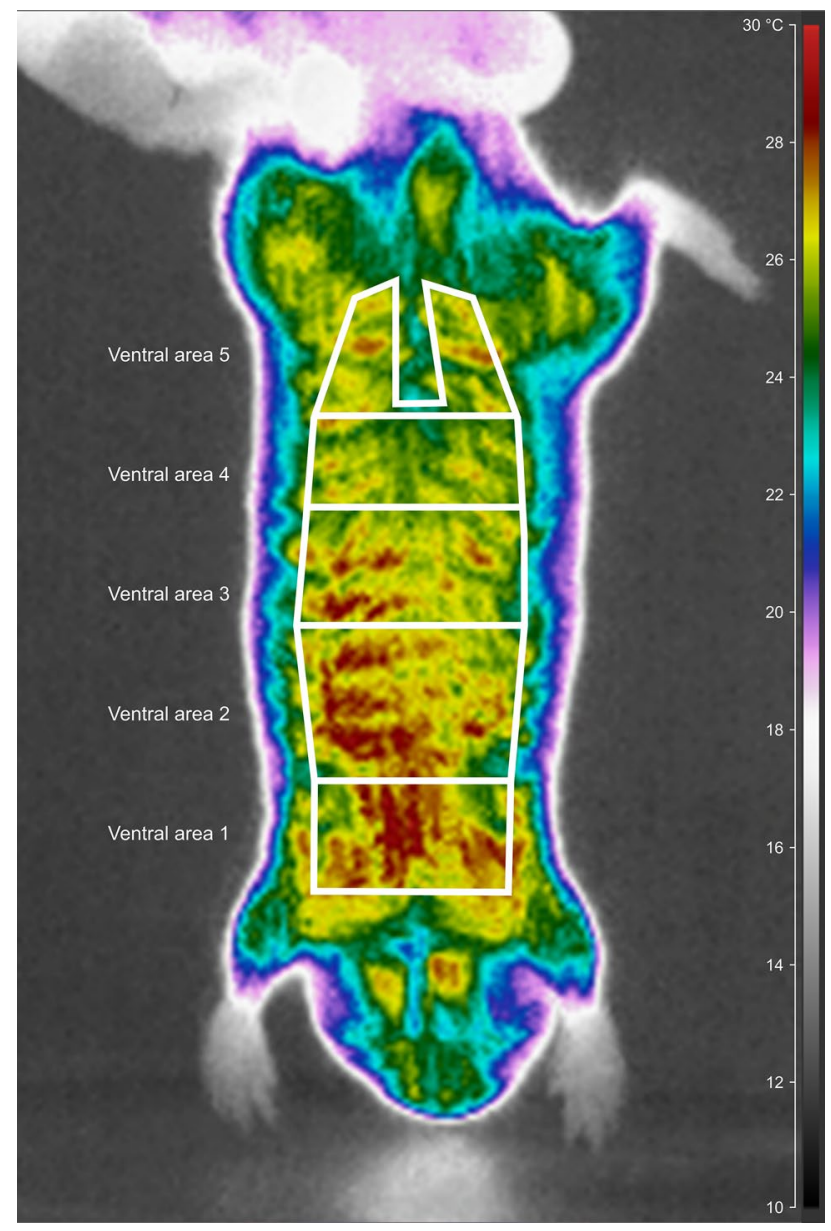

Figure 1. A schematic illustration of the layout of the five ventral areas for which surface temperatures were measured. The background is an infrared thermogram of the Ansell's mole-rat, F. anselli taken after acclimation at $10{ }^{\circ} \mathrm{C}$. The figure was prepared using the program Inkscape 0.92 (https://inkscape.org/).

set to 0.97 (e.g. $\left.{ }^{60}\right)$; air humidity, air temperature, and reflected temperature were entered as means of experimental room humidity and air temperature during the course of $\mathrm{T}_{\mathrm{s}}$ measurement of each species at given $\mathrm{T}_{\mathrm{a}}$; distance was set as the distance of camera lens from the animal. Although Šumbera et al. ${ }^{31}$ identified a few other body surface areas through which body heat is mainly passively dissipated in mole-rats (peripalpebral, nose, and ear area), we did not include them in our study due to their relatively small area, and thus very low contribution to overall heat dissipation.

Processed thermograms were used to infer mean $\mathrm{T}_{\mathrm{s}}$ of the whole ventral and dorsal body region, and the feet necessary for the calculation of $\mathrm{T}_{\text {diff. }}$ The analysed body regions were manually marked out with a polygonal region of interest in the CorePlayer (see Fig. 1 as an example for polygon of the whole venter). The region of interest was adjusted to fit onto the part of the body region of the particular individual perpendicularly oriented to the camera lens. Additionally, the venter was divided in the anterior-posterior axis into five areas (Fig. 1: 1-between the front legs, 2-to the widest part of the chest, 3-to the end of the rib cage, 4-to the hips, and 5-between hind legs without the anogenital area).

Data analyses. In all analyses performed in this study, $\mathrm{T}_{\text {diff }}$ was used as a dependent variable assuming Gaussian error distribution. In all models described below, body region (the dorsum, the venter, and feet), social organisation (social and solitary), and ventral area (1-5) were treated as explanatory categorical variables, whereas $T_{a}$ was treated as a covariate. Means $\pm S D$ are given throughout the text. The sex of the tested animals was not included as an explanatory variable, mainly because of a relatively low number of males and females tested. Nevertheless, we did not expect any differences because there are no remarkable sex differences in thermal biology of subterranean rodents apart from body mass if females are not pregnant or lactating pups ${ }^{25}$. To test our hypotheses, we fitted the models on subsets of data divided according to body region and selected $\mathrm{T}_{\mathrm{a}}$ values. All analyses were carried out in $\mathrm{R}^{61}$ and all figures were edited using the program Inkscape 0.92 (https://inkscape. $\operatorname{org} /)$. 
$T_{b}, T_{s,}$ and $T_{\text {diff }}$ over the $T_{a}$ gradient. Prior to testing of our hypotheses, we performed the following basic statistical exploratory analyses of $\mathrm{T}_{\mathrm{b}}$ and $\mathrm{T}_{\mathrm{s}}$. For each species, we firstly calculated a piecewise linear regression implemented in the $\mathrm{R}$ package Segmented ${ }^{62}$ to assess whether there is a breakpoint $T_{a}$, at which the regression curve characterising the change in $\mathrm{T}_{b}$ (expressed as mean values for each $\mathrm{T}_{\mathrm{a}}$ for each species) for a given species changes its slope. Secondly, we calculated a linear regression to characterise a change in $\mathrm{T}_{\mathrm{s}}$ (expressed as mean values for each $\mathrm{T}_{\mathrm{a}}$ for each species) in response to increasing $\mathrm{T}_{\mathrm{a}}$. We used Bonferroni procedure to correct the $\alpha$ of the tests since we calculated one piecewise linear regression for $\mathrm{T}_{\mathrm{b}}$ for each of the seven species (adjusted $\alpha=0.0071$ ) and 21 linear regressions for $T_{s}$ (adjusted $\alpha=0.0024$ ).

For each species separately, we tested whether $\mathrm{T}_{\text {diff }}$ differs amongst the three body regions, i.e. the dorsum, the venter, and the feet, using GLS marginal models implemented in the nlme package ${ }^{63}$. One GLS model was calculated for each of three $\mathrm{T}_{\mathrm{a}} \mathrm{s}-10$ and $35^{\circ} \mathrm{C}$ as extremes in order to obtain information about $\mathrm{T}_{\text {diff }}$ in cold and hot conditions, respectively, and $30^{\circ} \mathrm{C}$ which represents $\mathrm{TNZ}$ of all the studied species (Table 1). In all GLS models, the body region was the explanatory variable, and the identity of tested individuals was included to avoid pseudo-replication. We used the Bonferroni procedure to correct the significance level of the tests because we tested each $\mathrm{T}_{\mathrm{a}}$ separately for seven species and three $\mathrm{T}_{\mathrm{a}} \mathrm{s}$ (adjusted $\alpha=0.0024$ ), and then performed a similar post-hoc comparison 13-times (adjusted $\alpha=0.0038$ ).

For each species separately, we first calculated three linear regressions to test whether the slope characterising the change of $\mathrm{T}_{\text {diff }}$ in response to increasing $\mathrm{T}_{\mathrm{a}}$ for each of the three body regions is different from zero. For each body region, $T_{\text {diff }}$ value for a given $T_{a}$ was calculated as the mean obtained from all individuals within a given species, for which we obtained a complete set of $\mathrm{T}_{\mathrm{s}}$ values from all three body regions at all six $\mathrm{T}_{\mathrm{a}} \mathrm{s}$. Afterwards, a homogeneity-of-slopes model was calculated to test whether these three regression lines are parallel to each other, i.e. there is no interaction between body region and $\mathrm{T}_{\mathrm{a}}$. The function "emtrends" implemented in the R package emmeans ${ }^{64}$ was used to calculate post-hoc comparisons to find differences between the slopes for the dorsum, the venter, and the feet in these models. We used the Bonferroni procedure to correct the significance level of the tests we performed for each of the seven species: (a) three similar regression models (adjusted $\alpha=0.0024$ ) and (b) altogether seven homogeneity-of-slope models with a post-hoc test (adjusted $\alpha=0.0071$ ).

$T_{\text {diff }}$ of the three body regions in solitary and social species. To assess the effect of the social organization on $\mathrm{T}_{\text {diff }}$ (expressed as a mean value for each $\mathrm{T}_{\mathrm{a}}$ for each species) in each of the three body regions, we fitted Generalized Linear Mixed Models in a Bayesian framework using Markov Chain Monte Carlo sampling algorithm (MCMC) implemented in the R package $M C M C g l m m^{65}$. This approach was used to account for nonindependence in $\mathrm{T}_{\text {diff }}$ measurements arising due to shared phylogenetic ancestry, and therefore a random effect of phylogeny was included in all models. We controlled for phylogenetic relatedness using the subset tree of the mammal phylogeny by Upham et al. ${ }^{66}$. The set of subtrees was retrieved via an online tool: vertlife.org/phylosubsets/. The maximum credibility tree was then inferred using the $\mathrm{R}$ package phangorn $^{67}$, and taxa labels were changed using the $\mathrm{R}$ package phytools ${ }^{68}$ in order to merge the taxa with the comparative dataset.

Parameter estimates for fixed and random effects of each model were obtained from sampling posterior distributions by running 2,500,000 MCMC iterations with a burn-in period of $20 \%$ and a thinning interval sampling each 1000th iteration. Estimates of each parameter are thus based on 2000 samples from a posterior distribution. In all models, we used weakly informative priors for variance components $(\mathrm{V}=1, v=0.02)$, and a default prior specification for fixed effects, i.e. mean centred on zero with a very large variance $\left(\mu=0, V=10^{8}\right)$, to let the posterior be determined mostly by the information in the data. Mixing and convergence of MCMC chains were assessed by visual inspection of both time-series and density plots, as well as by calculating autocorrelation among successive MCMC samples. There was no apparent trend among MCMC samples in time-series plots, and autocorrelation was low in each fitted model. Effective sample size was $\sim 2000$ for all estimated parameters in all models, suggesting generally good mixing and convergence properties of MCMC chains.

For each of the three body regions separately, we fitted a model of the formula: $T_{\text {diff }} \sim T_{a}+$ social organisation $+\mathrm{T}_{\mathrm{a}}$ : social organisation (the same $\mathrm{T}_{\mathrm{diff}}$ datasets as for linear regressions were used for these models). Beside the random effect of the phylogeny accounting for evolutionary history of the studied taxa, we included also a random effect of species to account for species-specific effects on the variability in $\mathrm{T}_{\text {diff }}$ in response to $\mathrm{T}_{\mathrm{a}}$. This model allowed us to test whether the slopes for the change in $\mathrm{T}_{\text {diff }}$ as a response to increasing $\mathrm{T}_{\mathrm{a}}$ differ between solitary and social species. Interaction term was considered only when its effect in a model was significant (see highest posterior density (HPD) intervals and/or pMCMC in Table 3), and the deviance information criterion (DIC) indicated a better fit (lower DIC) of the model with than without interaction. If the effect of interaction was not significant, we ran the model without the interaction term, and interpreted only the effects of $\mathrm{T}_{\mathrm{a}}$ and social organization, respectively.

$\mathbf{T}_{\text {diff }}$ along the venter in solitary and social species. For each species individually, we tested whether $\mathrm{T}_{\text {diff }}$ differs among the five ventral areas using GLS models. One GLS model was calculated for each $\mathrm{T}_{\mathrm{a}}$ of 10,30 and $35^{\circ} \mathrm{C}$. In all GLS models, the ventral area was the explanatory variable (a factor with five levels: ventral area 1 -ventral area 5, see Fig. 1). We used the Bonferroni procedure to correct the significance level of the tests since we tested each of three $T_{a}$ s separately for seven species (adjusted $\alpha=0.0024$ ). In all GLS models, an identity of tested individuals was included to avoid pseudo-replication.

In addition, for each of the three $\mathrm{T}_{\mathrm{a}}$, we fitted one MCMCglmm of the form: $\mathrm{T}_{\text {diff }} \sim$ ventral area + social organisation + ventral area: social organisation, with random effects of the phylogenetic relatedness and species. This model allowed us to test whether the pattern of mean change in $\mathrm{T}_{\text {diff }}$ (calculated as the mean from all individuals of each species entering GLS analysis mentioned above) across five ventral areas differed between solitary and social species. The effect of interaction term was considered significant if the HPD intervals did not 


\begin{tabular}{|c|c|c|c|c|c|c|}
\hline Species & $\begin{array}{l}T_{a} \text { breaking point for } \\
T_{b}\left({ }^{\circ} \mathrm{C}\right)\end{array}$ & $\begin{array}{l}\text { Slope before the } \\
\text { breaking point of } T_{b}(p \\
\text { value) }\end{array}$ & $\begin{array}{l}\text { Slope after the breaking } \\
\text { point of } T_{b}\end{array}$ & $\begin{array}{l}T_{s} \text { Dorsum (F and } p \\
\text { value) }\end{array}$ & $T_{s}$ Venter ( $F$ and $p$ value) & $\mathrm{T}_{\mathrm{s}}$ Feet ( $\mathrm{F}$ and $p$ value) \\
\hline B. suillus & $27.5 \pm 0.9$ & $0.052 \pm 0.010(0.035)$ & $0.244 \pm 0.033$ & $609.6,1.6 \times 10^{-5 *}$ & $850.9,8.2 \times 10^{-6 *}$ & $125.5,3.6 \times 10^{-4 \star}$ \\
\hline G. capensis & $28.6 \pm 1.4$ & $0.048 \pm 0.020(0.137)$ & $0.264 \pm 0.066$ & $386.6,3.9 \times 10^{-5 *}$ & $157.5,2.3 \times 10^{-4 \star}$ & $216.1,1.2 \times 10^{-4 \star}$ \\
\hline C. hottentotus & $29.3 \pm 0.2$ & $0.069 \pm 0.005(0.004)^{\star}$ & $0.397 \pm 0.015$ & $615.7,1.6 \times 10^{-5 *}$ & $263.6,8.4 \times 10^{-5 x}$ & $56.1,0.0017^{\star}$ \\
\hline F. anselli & $28.8 \pm 0.9$ & $0.072 \pm 0.019(0.064)$ & $0.361 \pm 0.067$ & $137.3,3.0 \times 10^{-4 \star}$ & $74.1,0.001^{*}$ & $160.0,2.3 \times 10^{-4 *}$ \\
\hline F. "Nsanje" & $26.8 \pm 0.5$ & $-0.030 \pm 0.012(0.131)$ & $0.054 \pm 0.040$ & $309.1,6.1 \times 10^{-5 *}$ & $52.1,0.002^{*}$ & $1229.7,3.9 \times 10^{-6 x}$ \\
\hline S. cyanus & $23.1 \pm 1.1$ & $0.002 \pm 0.025(0.942)$ & $0.274 \pm 0.035$ & $1060.3,5.3 \times 10^{-6 *}$ & $670.9,1.3 \times 10^{-5 *}$ & $350.4,4.8 \times 10^{-5 *}$ \\
\hline N. galili & $26.6 \pm 1.6$ & $0.059 \pm 0.013(0.047)$ & $0.192 \pm 0.044$ & $1036.3,5.5 \times 10^{-6 *}$ & $921.5,7.0 \times 10^{-6 *}$ & $382.4,4.0 \times 10^{-5 *}$ \\
\hline
\end{tabular}

Table 2. Results of piecewise linear regressions characterising a change in core body temperature $\left(\mathrm{T}_{\mathrm{b}}\right)$ and linear regressions characterising a change in the surface temperature $\left(\mathrm{T}_{\mathrm{s}}\right)$ for three body regions in response to increasing ambient temperature $\left(\mathrm{T}_{\mathrm{a}}\right)$ in seven subterranean rodent species. Breaking points and slopes are provided as mean \pm SEM; $p$ values for the slopes before the breaking point are in parentheses; statistically significant tests after the Bonferroni procedure $\alpha=0.0071$ for $T_{b}$ and $\alpha=0.0024$ for $T_{s}$ are marked with asterisks.

include zero (see HPD intervals and/or pMCMC in Table 4), and DIC of the model with interaction was lower than that of the model without it.

Ethical approval. The experimental procedures in the Czech Republic were approved by the University of South Bohemia Animal Welfare committee and Ministry of Education, Youth and Sports of the Czech Republic (Permission no. MSMT-26065/2014-12). The experimental procedures in South Africa were approved by University of Pretoria Ethics Committee (Permission no. EC069-16). All procedures were performed in accordance with relevant guidelines and regulations.

\section{Results}

$\mathbf{T}_{\mathrm{b},} \mathbf{T}_{\mathrm{s} \text {, }}$ and $\mathrm{T}_{\text {diff }}$ over the $\mathrm{T}_{\mathrm{a}}$ gradient. In all species apart from C. hottentotus and S. cyanus, $\mathrm{T}_{\mathrm{b}}$ was stable from 10 up to $25^{\circ} \mathrm{C}$ (the slopes of segmented regressions were close to 0 ), showing breaking points between 26.6 and $28.8^{\circ} \mathrm{C}$, after which $\mathrm{T}_{\mathrm{b}}$ started to increase (see Table 2 for details). For C. hottentotus, $\mathrm{T}_{\mathrm{b}}$ increased across the whole $\mathrm{T}_{\mathrm{a}}$ range (the slope was significantly different from 0 for $\mathrm{T}_{\mathrm{b}}$ values before the breaking point), but there was a relatively steeper increase between 30 and $35^{\circ} \mathrm{C}$ (breaking point at $29.3 \pm 0.2^{\circ} \mathrm{C}$, Table 2). For S. cyanus, $\mathrm{T}_{\mathrm{b}}$ was stable only from 10 to $20^{\circ} \mathrm{C}$, with a breaking point at $\mathrm{T}_{\mathrm{a}}$ of $23.1 \pm 1.1^{\circ} \mathrm{C}$.

Surface temperature for the dorsum, the venter, and the feet increased in all species over the range of $\mathrm{T}_{\mathrm{a}}$ (Linear regressions, all $p<0.002$ were significant after the Bonferroni procedure, Fig. 2 and Table 2). In contrast to $\mathrm{T}_{\mathrm{b}}, \mathrm{T}_{\mathrm{s}}$ of all three regions showed markedly higher differences among the species, with the highest value for the venter at lower $\mathrm{T}_{\mathrm{a}} \mathrm{s}$, but these differences became smaller at 30 and $35^{\circ} \mathrm{C}$ (Fig. 2).

For each of the seven species, $\mathrm{T}_{\text {diff }}$ differed among the three body regions at $10^{\circ} \mathrm{C}(p<0.0001$, Supplementary Table S2). In N. galili, F. anselli, F. "Nsanje", and S. cyanus, $\mathrm{T}_{\text {diff }}$ was the lowest for the venter, and the highest for the feet, with the dorsum having intermediate $\mathrm{T}_{\text {diff }}$ significantly different from both $(p<0.001$, for all pairwise comparisons see Supplementary Table S2). In B. suillus, G. capensis, and C. hottentotus, $\mathrm{T}_{\mathrm{diff}}$ was lower only for the venter than the dorsum $(p<0.001)$, and the feet did not differ from either of the two.

At $30{ }^{\circ} \mathrm{C}, \mathrm{T}_{\text {diff }}$ differed among the three body regions in N. galili, B. suillus, and F. anselli only $(p<0.0001$, Supplementary Table S2). While both the venter and the feet had significantly lower $\mathrm{T}_{\text {diff }}$ than the dorsum in $N$. galili $(p<0.001), \mathrm{T}_{\text {diff }}$ was lower for the feet than for both the venter and the dorsum in B. suillus $(p<0.001)$. In $F$. anselli, the ventral $\mathrm{T}_{\text {diff }}$ was lower than the dorsal one, with $\mathrm{T}_{\text {diff }}$ of the feet being the highest $(p<0.001)$.

At $35^{\circ} \mathrm{C}, \mathrm{T}_{\text {diff }}$ differed among the three body regions only in N. galili, B. suillus, and G. capensis $(p<0.0001$, Supplementary Table S2). The feet of $N$. galili had lower $\mathrm{T}_{\text {diff }}$ than the venter and the dorsum, with the latter having the highest $\mathrm{T}_{\text {diff }}(p<0.001)$. In both B. suillus and G. capensis, the feet had lower $\mathrm{T}_{\text {diff }}$ than both the dorsum and the venter $(p<0.001)$ which had similar $\mathrm{T}_{\text {diff. }}$.

For each of the seven species, $\mathrm{T}_{\text {diff }}$ decreased with increasing $\mathrm{T}_{\mathrm{a}}$ in all three body regions (see Table 3 for statistical details and Fig. 3). Among the three body regions, the ventral $\mathrm{T}_{\text {diff }}$ showed the smallest change in response to increasing $\mathrm{T}_{\mathrm{a}}$ (i.e. a less steep slope), and it differed significantly from those of both the dorsum and the feet in five species. In S. cyanus, it differed from the feet only, and in C. hottentotus, no differences among all three respective slopes were found. Besides, the slopes for the dorsum were significantly steeper than slopes for the feet in F. anselli, F. "Nsanje", S. cyanus, and N. galili.

$T_{\text {diff }}$ of the three body regions in solitary and social species. The comparison among the slopes of regression lines characterising the response of $\mathrm{T}_{\text {diff }}$ to increasing $\mathrm{T}_{\mathrm{a}}$ for the dorsum, the venter, and the feet differed between solitary and social species (Fig. 4). For the dorsum, $\mathrm{T}_{\text {diff }}$ was significantly higher in solitary than in social species across the whole $\mathrm{T}_{\mathrm{a}}$ range $(\mathrm{pMCMC}<0.0001)$, and it decreased relatively more in solitary (slope -0.52 ) than in social species (slope -0.39) for a given increase in $\mathrm{T}_{\mathrm{a}}$ (Fig. 4A and Table 4, DIC $=134.4$ and 119.8 for models without and with the interaction between $\mathrm{T}_{\mathrm{a}}$ and social organisation, respectively). For the venter, the slopes characterising the change in $\mathrm{T}_{\text {diff }}$ in response to increasing $\mathrm{T}_{\mathrm{a}}$ did not differ between solitary and social species (slope -0.23 , DIC $=93.4$ and 95.6 for models without and with the interaction between $\mathrm{T}_{\mathrm{a}}$ and 




Figure 2. Core body temperatures and surface temperatures of the dorsum, the venter, and the feet measured across the range of ambient temperatures in seven subterranean rodent species. Means \pm SD are depicted. The figure was prepared using the program Inkscape 0.92 (https://inkscape.org/).

social organisation, respectively; $\mathrm{pMCMC}=0.884)$, but there was a tendency $(\mathrm{pMCMC}=0.079)$ for higher $\mathrm{T}_{\text {diff }}$ in solitary compared with social species (Fig. $4 \mathrm{~B}$ and Table 4 ). For the feet, $\mathrm{T}_{\text {diff }}$ did not differ between solitary and social species across the $\mathrm{T}_{\mathrm{a}}$ range (slope -0.59 , Fig. $4 \mathrm{C}$, and Table 4 , DIC $=145.8$ and 148.1 for models without and with the interaction between $\mathrm{T}_{\mathrm{a}}$ and social organisation, respectively; $\mathrm{pMCMC}=0.902$ ).

$\mathrm{T}_{\text {diff }}$ along the venter in solitary and social species. The $\mathrm{T}_{\text {diff }}$ for the five ventral areas varied for each of the seven species at $\mathrm{T}_{\mathrm{a}}$ of 10,30 , but not at $35^{\circ} \mathrm{C}$ (Table 5; Supplementary Fig. S1; see also Fig. 5 for the comparison of $\mathrm{T}_{s}$ pattern of the venter at $30^{\circ} \mathrm{C}$ for one solitary and one social mole-rat). In the N. galili, F. anselli, F. "Nsanje", $\mathrm{T}_{\text {diff }}$ varied among the five ventral areas at both 10 and $30^{\circ} \mathrm{C}$, whereas for C. hottentotus and S. cyanus, it differed at $30^{\circ} \mathrm{C}$ only. At $35^{\circ} \mathrm{C}$, there were no differences in $\mathrm{T}_{\text {diff }}$ among the five ventral areas in all species. In solitary B. suillus and G. capensis, the venter was thermally homogeneous at all $\mathrm{T}_{\mathrm{a}} \mathrm{s}$. There were no significant differences in the pattern of the $\mathrm{T}_{\text {diff }}$ change among the five ventral areas between solitary and social species in either of the three $\mathrm{T}_{\mathrm{a}} \mathrm{s}$ (see Table 6 for statistical details; at $10^{\circ} \mathrm{C}$ : $\mathrm{DIC}=65.2$ and 72.7 , at $30^{\circ} \mathrm{C}$ : $\mathrm{DIC}=-3.6$ and 3.1 and at $35^{\circ} \mathrm{C}$ : DIC $=-44.1$ and -42.5 ; the first and second DIC value are for models without and with the interaction between the ventral area and social organisation, respectively). 


\begin{tabular}{|c|c|c|c|c|c|c|c|}
\hline \multirow[b]{3}{*}{ Species } & \multicolumn{3}{|c|}{ Results of linear regressions testing non-zero slopes } & \multicolumn{4}{|c|}{ Results of homogeneity-of-slope models } \\
\hline & \multirow{2}{*}{$\begin{array}{l}\text { Dorsum }\left(R^{2}\right. \\
\text { adj })^{\mathrm{a}}\end{array}$} & \multirow[b]{2}{*}{ Venter $\left(\mathbf{R}^{2} \text { adj }\right)^{\mathbf{a}}$} & \multirow[b]{2}{*}{ Feet $\left(\mathbf{R}^{2} \text { adj }\right)^{\mathbf{a}}$} & \multirow{2}{*}{$\begin{array}{l}\text { Body } \\
\text { region } \times T_{a}^{b}\end{array}$} & \multicolumn{3}{|c|}{$p$ value of post-hoc comparison } \\
\hline & & & & & V versus $D^{\mathbf{a}}$ & V versus $F^{a}$ & $D$ versus $F^{a}$ \\
\hline B. suillus & $\begin{array}{l}\mathrm{t}=-11.1 \\
p<0.001^{\star}(0.96)\end{array}$ & $\begin{array}{l}\mathrm{t}=-6.1 \\
p<0.001^{*}(0.88)\end{array}$ & $\begin{array}{l}\mathrm{t}=-7.1 \\
p=0.002^{*}(0.91)\end{array}$ & $\begin{array}{l}\mathrm{F}=12.1 \\
p=0.001^{*}\end{array}$ & $0.003^{*}$ & $0.003^{*}$ & 0.999 \\
\hline G. capensis & $\begin{array}{l}\mathrm{t}=-38.0 \\
p<0.001^{*}(1.00)\end{array}$ & $\begin{array}{l}\mathrm{t}=-10.0 \\
p<0.001^{*}(0.95)\end{array}$ & $\begin{array}{l}\mathrm{t}=-21.4 \\
p<0.001^{\star}(0.99)\end{array}$ & $\begin{array}{l}\mathrm{F}=54.2 \\
p<0.001^{*}\end{array}$ & $<0.001^{*}$ & $<0.001^{*}$ & 0.552 \\
\hline C. hottentotus & $\begin{array}{l}\mathrm{t}=-13.3 \\
p<0.001^{*}(0.97)\end{array}$ & $\begin{array}{l}\mathrm{t}=-10.4 \\
p<0.001^{\star}(0.96)\end{array}$ & $\begin{array}{l}\mathrm{t}=-11.8 \\
p<0.001^{\star}(0.97)\end{array}$ & $\mathrm{F}=8.5, p=0.005^{*}$ & $0.013^{*}$ & $0.008^{*}$ & 0.956 \\
\hline F. anselli & $\begin{array}{l}\mathrm{t}=-25.0 \\
p<0.001^{\star}(0.99)\end{array}$ & $\begin{array}{l}\mathrm{t}=-10.0 \\
p<0.001^{\star}(0.95)\end{array}$ & $\begin{array}{l}\mathrm{t}=-13.4 \\
p<0.001^{\star}(0.97)\end{array}$ & $\begin{array}{l}\mathrm{F}=66.2 \\
p<0.001^{\star}\end{array}$ & $0.004^{*}$ & $<0.001^{*}$ & $<0.001^{*}$ \\
\hline F. "Nsanje" & $\begin{array}{l}\mathrm{t}=-10.6 \\
p<0.001^{*}(0.96)\end{array}$ & $\begin{array}{l}\mathrm{t}=-14.9 \\
p<0.001^{\star}(0.98)\end{array}$ & $\begin{array}{l}\mathrm{t}=-14.2 \\
p<0.001^{\star}(0.98)\end{array}$ & $\begin{array}{l}\mathrm{F}=31.7 \\
p<0.001^{\star}\end{array}$ & $0.007^{*}$ & $<0.001^{*}$ & $0.003^{*}$ \\
\hline S. cyanus & $\begin{array}{l}\mathrm{t}=-10.5 \\
p<0.001^{*}(0.96)\end{array}$ & $\begin{array}{l}\mathrm{t}=-8.4 \\
p=0.001^{\star}(0.93)\end{array}$ & $\begin{array}{l}\mathrm{t}=-10.1 \\
p<0.001^{\star}(0.95)\end{array}$ & $\begin{array}{l}\mathrm{F}=21.1 \\
p<0.001^{\star}\end{array}$ & 0.231 & $<0.001^{*}$ & $0.002^{*}$ \\
\hline N. galili & $\begin{array}{l}\mathrm{t}=-12.4 \\
p<0.001^{*}(0.97)\end{array}$ & $\begin{array}{l}\mathrm{t}=-14.4 \\
p<0.001^{*}(0.98)\end{array}$ & $\begin{array}{l}\mathrm{t}=-11.6 \\
p<0.001^{*}(0.96)\end{array}$ & $\begin{array}{l}\mathrm{F}=31.4 \\
p<0.001^{*}\end{array}$ & $0.004^{*}$ & $<0.001^{*}$ & $0.006^{\star}$ \\
\hline
\end{tabular}

Table 3. Results of the linear regressions testing whether the slopes characterising a decrease in the change of the difference between core body and surface temperatures $\left(\mathrm{T}_{\text {diff }}\right)$ in response to increasing ambient temperatures $\left(\mathrm{T}_{\mathrm{a}}\right)$ differ from zero for the dorsum $(\mathrm{D})$, venter $(\mathrm{V})$ and feet $(\mathrm{F})$ and of the homogeneity-ofslope models (Body region $\times \mathrm{T}_{\mathrm{a}}$ ) testing whether these slopes differ among the three body regions in seven subterranean rodent species. The degrees of freedom were 1 and 4 for the linear regressions and 2 and 12 for the homogeneity-of-slope models; the goodness of fit of the regression is presented by the adjusted $\mathrm{R}^{2}$; the $p$ value of post-hoc pairwise comparisons for the homogeneity-of-slope models are shown in the columns $\mathrm{V}$ vs. D, V vs. F, and D vs. F; statistically significant results after Bonferroni correction $\alpha=0.0024^{\mathrm{a}}$ or $\alpha=0.0071^{\mathrm{b}}$ applied are marked with an asterisk.

\section{Discussion}

To the best of our knowledge, this study represents the highest number of endotherm species, where heat dissipation has been analysed within a single study using the IRT approach. In several aspects, this allows us to generalise our findings for subterranean rodents. We found that the main heat dissipation areas in all species are present at the venter and the feet. With respect to the effect of sociality, solitary species dissipate less heat through the dorsum than social species and the same tendency was found for the venter. For the feet, there were no differences between both groups. Finally, the pattern of heat dissipation along the venter was not consistent between species and could not be attributed to sociality.

For the purpose of our study, we defined $\mathrm{T}_{\text {diff }}$ as the difference between $\mathrm{T}_{\mathrm{b}}$ and $\mathrm{T}_{\mathrm{s}}$ in each individual and each $\mathrm{T}_{\mathrm{a}}$ measured. The value of this parameter is predominantly driven by $\mathrm{T}_{s}$ which increases remarkably over the gradient of $\mathrm{T}_{\mathrm{a}}$ for all three body regions with $\mathrm{T}_{\mathrm{b}}$ being much more stable (Fig. 2). Applying this approach can be important especially in comparative studies using multiple species differing in $\mathrm{T}_{\mathrm{b}}$ and species-specific change of $\mathrm{T}_{\mathrm{b}}$ over the gradient of $\mathrm{T}_{\mathrm{a}}$. This can be illustrated by the results of the segmented analysis when the increase of $\mathrm{T}_{\mathrm{b}}$ started at $23.1^{\circ} \mathrm{C}$ as found in S. cyanus, but at $29.3^{\circ} \mathrm{C}$ as observed for C. hottentotus (Table 2).

Our results demonstrate that the tested body regions play different roles in heat dissipation in subterranean rodents. As predicted (based on $\left.{ }^{31,34}\right)$, at the coldest $\mathrm{T}_{\mathrm{a}}$ measured $\left(10^{\circ} \mathrm{C}\right)$ we found lower $\mathrm{T}_{\text {diff }}$ on the venter compared to the dorsum in all studied species (and in F. anselli, F. "Nsanje", S. cyanus, N. galili also compared to the feet) showing relatively higher heat dissipation from this body region (Fig. 3 and Supplementary Table S2). The warmer venter in lower $\mathrm{T}_{a} \mathrm{~s}$ compared to other body surfaces was recently also found in three social mole-rat species $^{35}$. This finding corresponds with the pattern found in some other mammals. A venter suitable for heat dissipation can be advantageous as its heat flow may be controlled behaviourally ${ }^{12,21,31,69}$. Although we did not quantify the behaviour of all individuals during the experiments, closing of a ventral thermal window by curling up into a ball was observed in most individuals at lower $\mathrm{T}_{\mathrm{a}} \mathrm{s}$ (see Supplementary Fig. S2). Adopting this posture, animals not only minimise heat losses through their venter, but also reduce their effective surface-to-volume ratio bringing additional energetic savings $\mathrm{s}^{70}$ (note that the same posture is adopted also by torpid small nonvolant mammals $\left.{ }^{71}\right)$. On the contrary, at high $\mathrm{T}_{\mathrm{a}} \mathrm{s}\left(\geq 30^{\circ} \mathrm{C}\right)$, tested animals usually exposed their venter to the environment mainly by lying on their back with the legs outstretched trying to maximize heat transfer to the surroundings (Supplementary Fig. S2). A large ventral thermal window should thus be advantageous, especially in subterranean mammals because they are predicted to lose the excessive metabolic heat during digging by means of conduction when the venter is in direct contact with the excavated soil and burrow floor ${ }^{36}$.

Our findings also confirm an important role of the feet in thermoregulation of subterranean rodents as has been also shown in two studies on African mole-rats ${ }^{31,35}$. In laboratory rats, the feet together with the distal parts of legs comprise around $10 \%$ of the total body surface and serve as an important heat dissipating region ${ }^{72}$. The feet of rodents adapted for digging and removing the soil are larger than in non-fossorial rodents ${ }^{73,74}$, and thus represent a significant proportion of the body surface. The importance of the feet in the thermoregulation of subterranean rodents is likely even higher because of lack of other body appendages, and due to their large surface-to-volume ratio. The feet are usually not well haired which, together with their bare pedal surface, makes them suitable for fast and effective heat transfer. Due to their relatively large size and heat convection via direct 

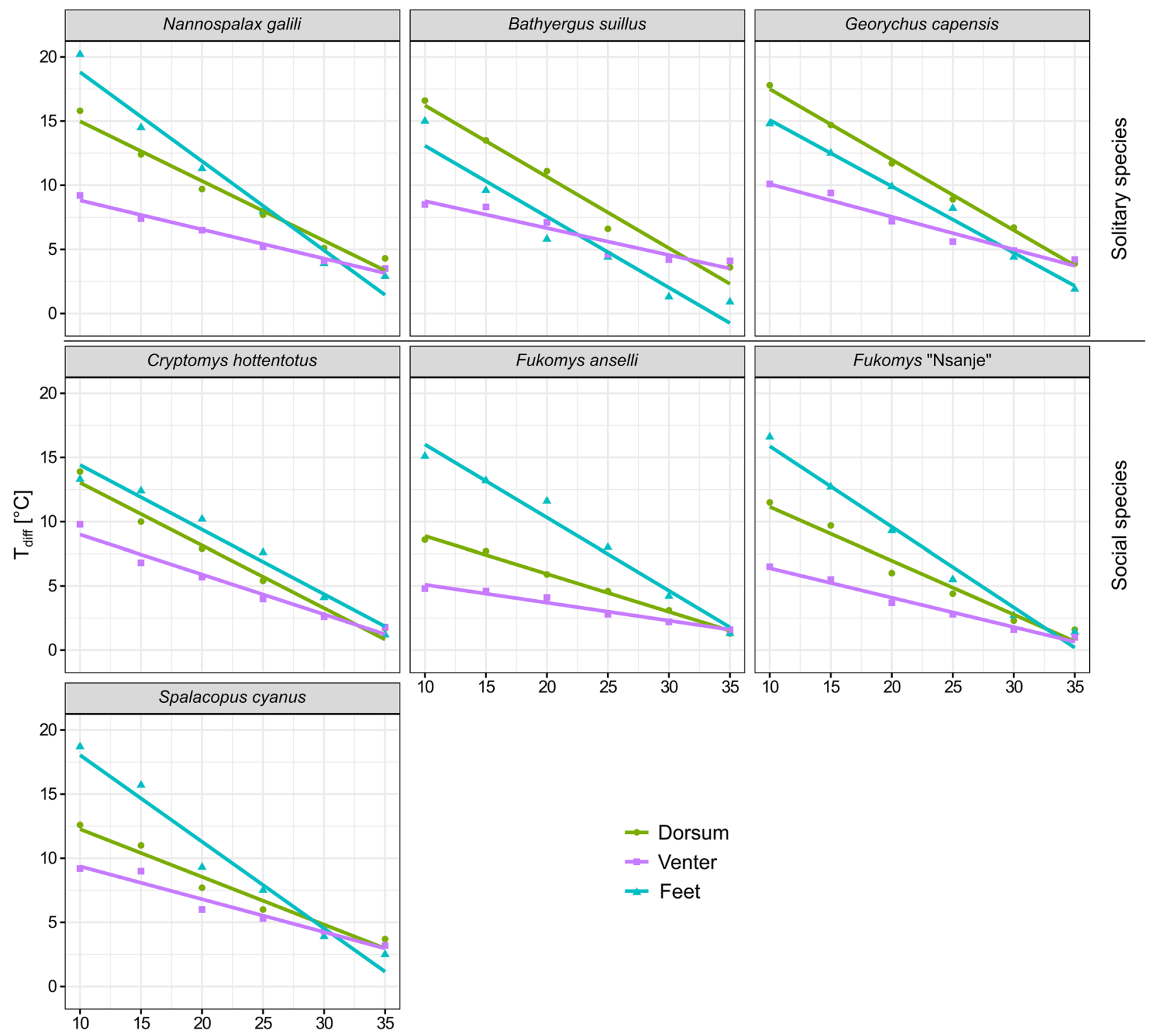

$$
\begin{aligned}
& =\text { Dorsum } \\
& =\text { Venter } \\
& =\text { Feet }
\end{aligned}
$$

\section{$\mathrm{T}_{\mathrm{a}}\left[{ }^{\circ} \mathrm{C}\right]$}

Figure 3. The difference between core body temperature and surface temperature $\left(\mathrm{T}_{\mathrm{diff}}\right)$ for the dorsum, the venter, and the feet across the range of ambient temperature $\left(\mathrm{T}_{\mathrm{a}}\right)$ in seven subterranean rodent species. Points indicate mean values, straight lines are the regression lines predicted by linear models. The figure was prepared using the program Inkscape 0.92 (https://inkscape.org/).

contact with the substrate, the feet are far more effective than small areas around the eyes or ears which were also found to lose heat in mole-rats ${ }^{31}$.

In this regard, our results indicate very effective vasoconstriction taking place in the feet to decrease heat losses at the lowest $\mathrm{T}_{\mathrm{a}} \mathrm{s}$. This is supported by the feet being the body region with the lowest $\mathrm{T}_{\mathrm{s}}$, and thus highest $\mathrm{T}_{\text {diff }}$ in four of seven tested species at $\mathrm{T}_{\mathrm{a}}$ of $10{ }^{\circ} \mathrm{C}$ (Fig. 2, 3, and Supplementary Table S2). The absence of significant differences between the feet and the other two body regions at this $\mathrm{T}_{\mathrm{a}}$ in B. suillus, G. capensis, C. hottentotus indicates a very effective insulative ability of their haired body surfaces rather than the absence of effective vasoconstriction in their feet. Importantly, at $35^{\circ} \mathrm{C}$, the feet $\mathrm{T}_{\text {diff }}$ was significantly smaller than the $\mathrm{T}_{\text {diff }}$ of other two body regions in three tested solitary species, N. galili, B. suillus, and G. capensis (Fig. 3, Supplementary Table S2). This demonstrates intensive vasodilatation and dissipation of the excessive body heat which cannot be effectively dissipated by other body parts because of the presence of well insulating fur (based on data on fur characteristics for all three species, Vejmělka and Šumbera unpubl. data). Heat dissipation via the feet is likely very relevant, similarly to the venter, especially during digging because of their contact with soil. McGowan et al. ${ }^{35}$ even suggested that the feet with reduced hair coverage are important at high $\mathrm{T}_{\mathrm{a}} \mathrm{s}$ when other conductive heat losses are working at their maximal capacity. Since the feet contribute to increased heat dissipation at high $\mathrm{T}_{\mathrm{a}} \mathrm{s}$, but effectively decrease heat loss at low $\mathrm{T}_{\mathrm{a}} \mathrm{s}$, they serve as a typical body-extremity-located thermal window similarly to other mammals (e.g. ${ }^{3-6}$ ). 


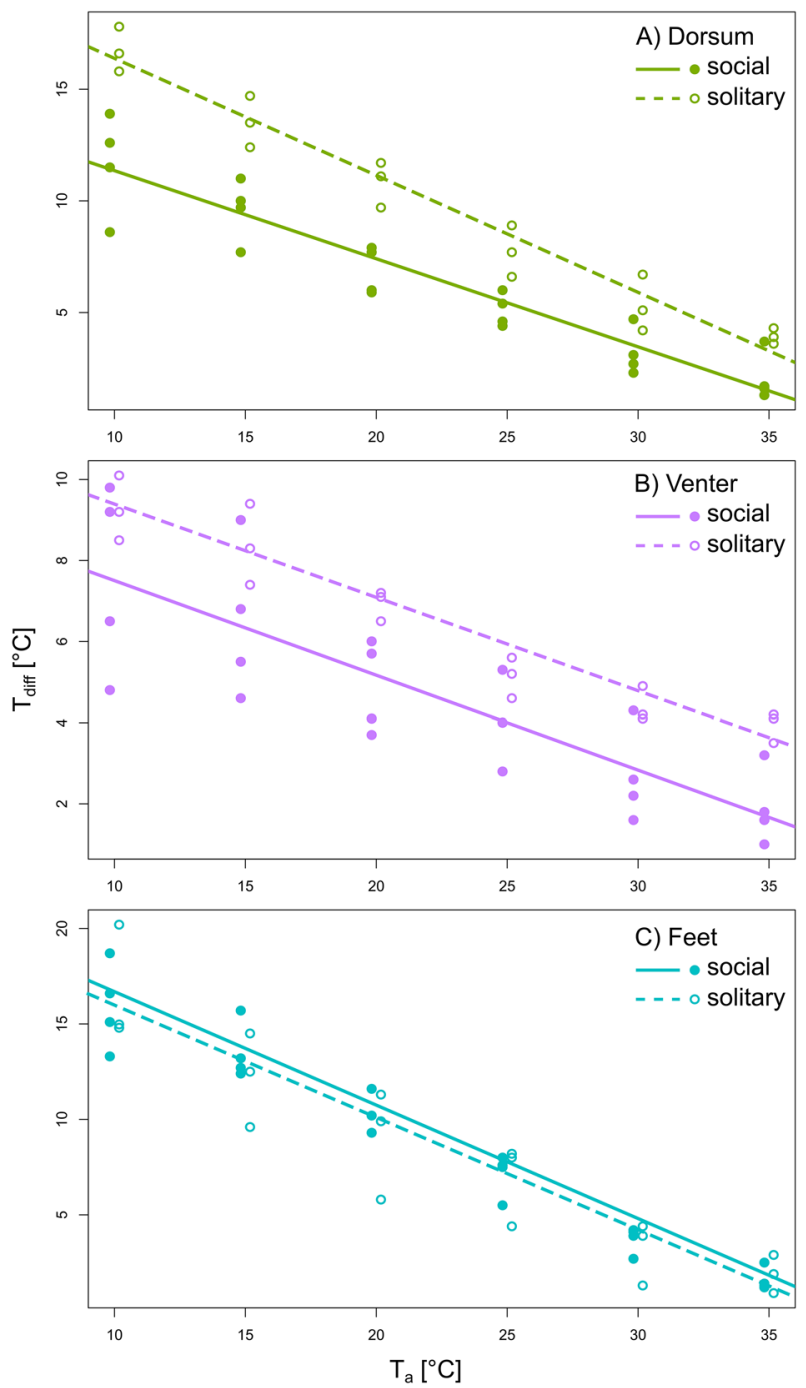

Figure 4. The difference between core body temperature and surface temperature $\left(\mathrm{T}_{\text {diff }}\right)$ in response to increasing ambient temperature $\left(\mathrm{T}_{\mathrm{a}}\right)$ for the dorsum $(\mathbf{A})$, the venter $(\mathbf{B})$, and the feet $(\mathbf{C})$ between solitary and social species. Lines are the regression lines predicted by MCMCglmm. The figure was prepared using the program Inkscape 0.92 (https://inkscape.org/).

The importance of the feet in heat exchange was supported also by behavioural observations during the experiment. At low $\mathrm{T}_{\mathrm{a}} \mathrm{s}$, we observed that many tested animals were sitting on the hind feet with the front feet not in contact with the cold floor (Supplementary Fig. S2). It was also documented that several individuals of $H$. argenteocinereus had some of their feet surprisingly warm while shivering at $10^{\circ} \mathrm{C}^{31}$. This indicates that the feet may play an active role in dissipation of excessive heat produced by shivering as suggested by authors, or alternatively, occasional warming of the feet could be related to protection against cold damage by repeated short-term redirection of blood flow into peripheral colder body parts, as showed across diverse mammalian taxa including foxes, rats, or humans (e.g. ${ }^{4,75,76}$ ).

We demonstrated that tested species and probably other subterranean rodents effectively combine heat dissipation through the venter and the feet, yet each of these body regions acts as a different type of thermal exchanger. The first type emits heat more or less continuously (as indicated by constantly relatively low $\mathrm{T}_{\text {diff, }}$, and by its less steep slope over the gradient of $\mathrm{T}_{\mathrm{a}}$ compared to the other two body regions; see Fig. 3), and is represented by being less furred, and thus less thermally insulated venter ${ }^{31}$. When necessary in cold conditions, heat dissipation through this surface can be reduced behaviourally by changing the body posture (see above). The second type is represented by the feet with the steeper slope of the $\mathrm{T}_{\text {diff }}$ change. In the cold temperatures, heat loss may be prevented effectively as for instance indicated in gerbils ${ }^{77}$. In this regard, the way in which these mechanisms, when acting simultaneously, contribute to heat dissipation is intriguing, and needs to be further explored in subterranean rodents and mammals in general.

Considering the effect of sociality on heat dissipation, Šumbera et al..$^{31}$ found that social F. mechowii had higher $\mathrm{T}_{\mathrm{s}}$ on both the venter and the dorsum, but not the feet compared with solitary H. argenteocinereus. Our results partially support the effect of sociality on heat dissipation in larger number of species. As expected, the 


\begin{tabular}{|l|l|l|l|c|c|}
\hline Body region & Fixed term & Estimate $(\boldsymbol{\beta})$ & $\mathbf{2 . 5} \%$ HPD & $\mathbf{9 7 . 5 \%}$ HPD & pMCMC \\
\hline \multirow{4}{*}{ Dorsum } & Intercept & 15.237 & 12.534 & 17.958 & \\
\cline { 2 - 6 } & $\mathrm{T}_{\mathrm{a}}$ & -0.394 & -0.437 & -0.349 & $<0.0001$ \\
\cline { 2 - 6 } & Social organisation (solitary) & 6.358 & 3.664 & 8.995 & 0.001 \\
\cline { 2 - 6 } & $\mathrm{T}_{\mathrm{a}} \times$ Social organisation & -0.131 & -0.190 & -0.059 & $<0.0001$ \\
\hline \multirow{5}{*}{ Venter } & Intercept & 9.870 & 6.637 & 13.007 & \\
\cline { 2 - 6 } & $\mathrm{T}_{\mathrm{a}}$ & -0.233 & -0.257 & -0.208 & $<0.0001$ \\
\cline { 2 - 6 } & Social organisation (solitary) & 1.962 & -0.124 & 4.427 & 0.079 \\
\cline { 2 - 6 } & $\mathrm{T}_{\mathrm{a}} \times$ Social organisation & 0.004 & -0.046 & 0.053 & 0.884 \\
\hline \multirow{5}{*}{ Feet } & Intercept & 22.6530 & 19.3105 & 26.4544 & \\
\cline { 2 - 6 } & $\mathrm{T}_{\mathrm{a}}$ & -0.591 & -0.636 & -0.543 & $<0.0001$ \\
\cline { 2 - 6 } & Social organisation (solitary) & -0.644 & -3.258 & 2.197 & 0.558 \\
\cline { 2 - 6 } & $\mathrm{T}_{\mathrm{a}} \times$ Social organisation & 0.005 & -0.092 & 0.093 & 0.902 \\
\hline
\end{tabular}

Table 4. Relationships between the difference between core body and surface temperature $\left(\mathrm{T}_{\mathrm{diff}}\right)$ of the three body regions, ambient temperature $\left(\mathrm{T}_{\mathrm{a}}\right)$, and social organisation (solitary vs. social) in seven species of subterranean rodents. 2.5\% HPD and 97.5\% HPD represent lower and upper highest posterior density intervals; $\mathrm{pMCMC}$ denotes to the $p$ value obtained from MCMCglmm; $\mathrm{T}_{\mathrm{a}} \times$ Social organisation $=$ interaction between $\mathrm{T}_{\mathrm{a}}$ and social organisation.

\begin{tabular}{|c|c|c|}
\hline Species & $\mathrm{T}_{\mathrm{a}}\left({ }^{\circ} \mathrm{C}\right)(n)$ & Fixed term: ventral area \\
\hline \multirow{3}{*}{ B. suillus } & $10(10)$ & $\mathrm{F}_{4,45}=0.7, p=0.616$ \\
\hline & $30(9)$ & $\mathrm{F}_{4,30}=1.3, p=0.302$ \\
\hline & $35(10)$ & $\mathrm{F}_{4,45}=0.4, p=0.817$ \\
\hline \multirow{3}{*}{ G. capensis } & $10(9)$ & $\mathrm{F}_{4,40}=2.6, p=0.054$ \\
\hline & $30(7)$ & $\mathrm{F}_{4,30}=1.8, p=0.160$ \\
\hline & $35(4)$ & $\mathrm{F}_{4,15}=0.7, p=0.593$ \\
\hline \multirow{3}{*}{ C. hottentotus } & $10(9)$ & $\mathrm{F}_{4,40}=3.9, p=0.010$ \\
\hline & $30(9)$ & $\mathrm{F}_{4,40}=8.0, p<0.001^{*}$ \\
\hline & $35(9)$ & $\mathrm{F}_{4,40}=4.0, p=0.008$ \\
\hline \multirow{3}{*}{ F. anselli } & $10(8)$ & $\mathrm{F}_{4,35}=14.7, p<0.001^{*}$ \\
\hline & $30(7)$ & $\mathrm{F}_{4,30}=16.4, p<0.001^{*}$ \\
\hline & $35(6)$ & $\mathrm{F}_{4,25}=3.9, p=0.014$ \\
\hline \multirow{3}{*}{ F. "Nsanje" } & $10(11)$ & $\mathrm{F}_{4,50}=39.5, p<0.001^{*}$ \\
\hline & $30(8)$ & $\mathrm{F}_{4,35}=11.3, p<0.001^{*}$ \\
\hline & $35(6)$ & $\mathrm{F}_{4,25}=0.4, p=0.814$ \\
\hline \multirow{3}{*}{ S. cyanus } & $10(2)$ & $\mathrm{F}_{4,5}=0.4, p=0.804$ \\
\hline & $30(3)$ & $\mathrm{F}_{4,10}=43.1, p<0.001^{*}$ \\
\hline & $35(5)$ & $\mathrm{F}_{4,20}=0.7, p=0.586$ \\
\hline \multirow{3}{*}{ N. galili } & $10(17)$ & $\mathrm{F}_{4,80}=6.1, p<0.001^{*}$ \\
\hline & $30(15)$ & $\mathrm{F}_{4,70}=8.7, p<0.001^{*}$ \\
\hline & $35(17)$ & $\mathrm{F}_{4,80}=1.4, p=0.239$ \\
\hline
\end{tabular}

Table 5. The results of GLS models comparing the difference between core body and surface temperature $\left(\mathrm{T}_{\text {diff }}\right)$ among the five ventral areas at ambient temperature $\left(\mathrm{T}_{\mathrm{a}}\right)$ of 10,30 and $35^{\circ} \mathrm{C}$ in each of the seven subterranean rodent species. For each $\mathrm{T}_{\mathrm{a}}$, the venter was tested separately; $n$ denotes to the number of individuals tested for each $\mathrm{T}_{\mathrm{a}}$; statistically significant results after Bonferroni correction $\alpha=0.0024$ applied are marked with an asterisk; post-hoc comparisons among the areas are depicted by letter combinations in Supplementary Fig. S1.

role of the feet in heat dissipation was independent of social organization, as demonstrated by almost identical regression lines for solitary and social species (Fig. 4C). On the contrary, solitary species had significantly higher $\mathrm{T}_{\text {diff }}$ on the dorsum across tested $\mathrm{T}_{\mathrm{a}} \mathrm{s}$, especially at lower temperatures (Fig. 4A). Solitary species thus conserve heat more effectively through this body region especially at lower $\mathrm{T}_{\mathrm{a}} \mathrm{s}\left(\mathrm{cf}^{31}{ }^{31}\right.$. Although the mean ventral $\mathrm{T}_{\text {diff }}$ of solitary species was about $2{ }^{\circ} \mathrm{C}$ higher across experimental $\mathrm{T}_{\mathrm{a}} \mathrm{s}$ (Fig. $4 \mathrm{~B}$ ), this difference only approached significance. This might be caused mainly by a large intraspecific variability of the ventral $\mathrm{T}_{\text {diff }}$ among the four studied social species (compare Fig. 4A,B). Indeed, S. cyanus and C. hottentotus had markedly higher $\mathrm{T}_{\text {diff }}$ than two Fukomys 
Cryptomys hottentotus

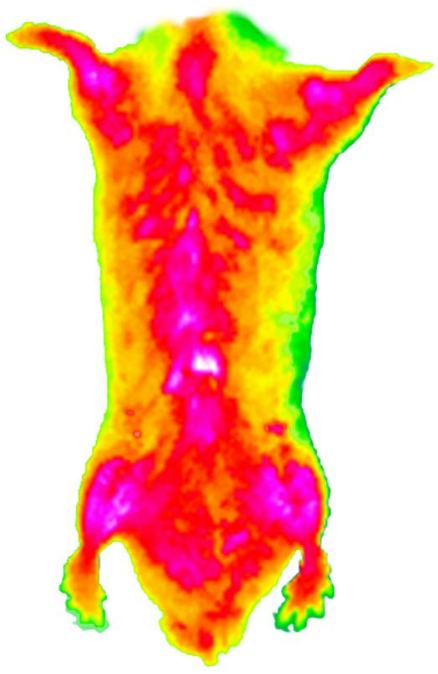

Georychus capensis

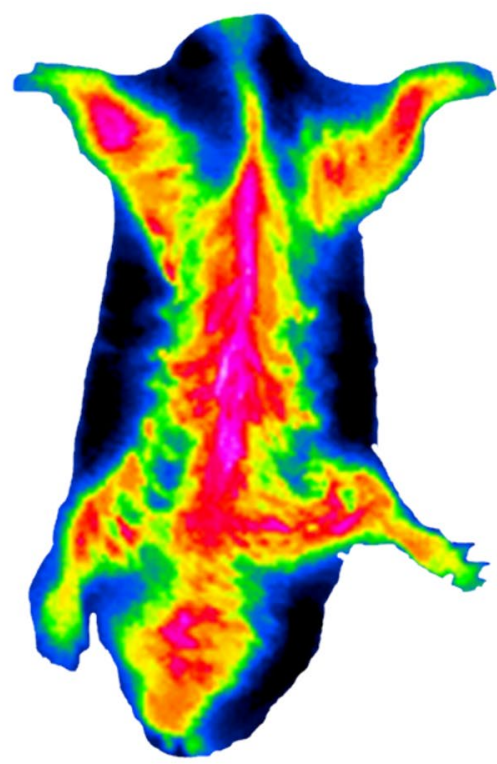

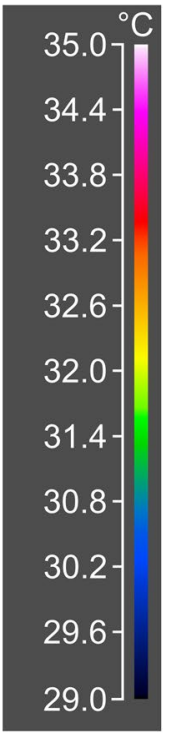

Figure 5. An example of thermogram showing the differences in surface temperature of the venter at $30^{\circ} \mathrm{C}$ between the solitary Cape mole-rat G. capensis and the social common mole-rat C. hottentotus. The figure was prepared using the program Inkscape 0.92 (https://inkscape.org/).

species at the lowest $\mathrm{T}_{\mathrm{a}}$ of $10^{\circ} \mathrm{C}$ (see Fig. 3). We may speculate that such difference can indicate better ventral fur insulation in these two species, as they occupy harsher environmental conditions compared to tropical habitats of both Fukomys species (see Table 1). Further studies that will focus on the fur quality including more species from various environmental conditions could help to better understand this concept.

Higher heat dissipation from the surface of social subterranean species is linked with lower insulative properties of their fur ${ }^{31,33}$. Dense heat conserving fur is probably not necessary in social species because they can take advantage of social thermoregulation at low $\mathrm{T}_{\mathrm{a}} \mathrm{s}^{37,38}$. While individuals of social species are temporarily single such as during digging, burrow maintaining, and patrolling, metabolic heat produced by their activities could help to keep a stable $\mathrm{T}_{\mathrm{b}}$ (c.f. ${ }^{36,78}$ ). On the contrary, solitary species cannot use huddling. Instead, solitary species can minimise body surfaces exposed to the environment solely by curling up during the rest, as observed in all solitary species at low $\mathrm{T}_{\mathrm{a}} \mathrm{s}$ in the present study, and also during several radio-tracking studies under natural conditions ${ }^{79-81}$. Denser and thus well insulating fur across the dorsum and flanks of solitary species ${ }^{31,33}$ is important because this body region is always exposed to the environment when the animal is rolled into a ball. On the other hand, less insulating fur in social species is advantageous at high $\mathrm{T}_{a} \mathrm{~s}$, or whilst digging when it is necessary to dissipate surplus metabolic heat to avoid overheating. In this situation, better heat conserving fur of solitary species complicates heat dissipation as we observed higher $\mathrm{T}_{\text {diff }}$ on the dorsum, and in some species also on the venter, compared to the feet at the highest studied $\mathrm{T}_{\mathrm{a}}$ in solitary species only (see Supplementary Table S2). Thus, their feet likely play a crucial role in heat dissipation at high $\mathrm{T}_{\mathrm{a}}$ and/or during digging in solitary species.

Different social organisation and fur characteristics resulting in different body heat dissipation may have relevant ecological consequences. For the naked mole-rat Heterocephalus glaber, the combination of small body mass and hairless surface resulting together in very high heat losses limits its occurrence in lowland areas of East Africa because it is not able to disperse through the cooler highlands in the western and northern borders of its distribution ${ }^{82}$. We may assume that higher heat losses in social species may handicap them during dispersal and forming of new families especially in colder climate if they disperse singly. Although it is very difficult to collect such information in nature, it seems that dispersing individuals of social species can stay alone for long period of time, likely for weeks, months, or even years ${ }^{45-48}$ facing high thermal challenges during that time. In this regard, although anecdotal, the radio-tracking of F. mechowii revealed interesting finding related to this phenomenon ${ }^{47}$. Lövy et al. ${ }^{47}$ found that a solitarily living female had a different circadian activity pattern and resting position than conspecific mole-rats living in a group. This female was most active during the hottest part of day, and usually rested in the curled-up body position while mole-rats from the family were most active during the night, and rested communally outstretched in their nest as indicated by a signal of their collars. Both changing of resting position and activity pattern likely minimised her heat losses. Interestingly, the peak occurred during the hottest part of the day and the pattern of its activity was more similar to that of the activity of the solitary $H$. argenteocinereus and N. galili $i^{79,80}$ than to F. mechowii living in a family group ${ }^{47}$. Besides, less insulating fur of social species could explain why the social $F$. whytei does not colonise generally colder Afromontane grasslands from the lower altitudes of the Nyika Plateau where it is common in contrast to the solitary H. argenteocinereus, even though there is a higher food supply and more easily workable soil in grasslands ${ }^{44}$.

Finally, we analysed whether $\mathrm{T}_{\text {diff }}$ differs along the venter, and if sociality influences the heterogeneity of ventral $\mathrm{T}_{\mathrm{diff}}$ distribution as suggested for two mole-rat species with contrasting sociality ${ }^{31}$. For this purpose, 


\begin{tabular}{|c|c|c|c|c|c|}
\hline $\mathrm{T}_{\mathrm{a}}\left({ }^{\circ} \mathrm{C}\right)$ & Fixed terms & Estimate $(\beta)$ & 2.5\% HPD & 77.5\% HPD & pMCMC \\
\hline \multirow{10}{*}{10} & (Intercept) & 7.828 & 1.728 & 13.867 & 0.026 \\
\hline & Ventral area 2 & -0.275 & -1.111 & 0.456 & 0.481 \\
\hline & Ventral area 3 & -0.099 & -0.899 & 0.668 & 0.817 \\
\hline & Ventral area 4 & 0.134 & -0.679 & 0.889 & 0.743 \\
\hline & Ventral area 5 & 0.478 & -0.311 & 1.253 & 0.225 \\
\hline & Social organisation (solitary) & 2.712 & -2.031 & 6.858 & 0.187 \\
\hline & Ventral area $2 \times$ social organisation (solitary) & 0.122 & -1.109 & 1.290 & 0.848 \\
\hline & Ventral area $3 \times$ social organisation (solitary) & 0.044 & -1.113 & 1.141 & 0.938 \\
\hline & Ventral area $4 \times$ social organisation (solitary) & -0.354 & -1.526 & 0.857 & 0.556 \\
\hline & Ventral area $5 \times$ social organisation (solitary) & -0.498 & -1.717 & 0.693 & 0.375 \\
\hline \multirow{10}{*}{30} & (Intercept) & 2.603 & 0.647 & 4.388 & 0.017 \\
\hline & Ventral area 2 & -0.111 & -0.421 & 0.181 & 0.461 \\
\hline & Ventral area 3 & -0.119 & -0.415 & 0.195 & 0.427 \\
\hline & Ventral area 4 & -0.030 & -0.351 & 0.253 & 0.846 \\
\hline & Ventral area 5 & -0.003 & -0.325 & 0.256 & 0.980 \\
\hline & Social organisation (solitary) & 2.053 & 0.444 & 3.786 & 0.034 \\
\hline & Ventral area $2 \times$ social organisation (solitary) & 0.097 & -0.352 & 0.559 & 0.657 \\
\hline & Ventral area $3 \times$ social organisation (solitary) & 0.049 & -0.390 & 0.494 & 0.834 \\
\hline & Ventral area $4 \times$ social organisation (solitary) & -0.181 & -0.637 & 0.253 & 0.409 \\
\hline & Ventral area $5 \times$ social organisation (solitary) & 0.092 & -0.340 & 0.526 & 0.683 \\
\hline \multirow{10}{*}{35} & (Intercept) & 1.441 & -0.949 & 3.734 & 0.173 \\
\hline & Ventral area 2 & -0.051 & -0.225 & 0.103 & 0.506 \\
\hline & Ventral area 3 & -0.037 & -0.188 & 0.122 & 0.641 \\
\hline & Ventral area 4 & 0.046 & -0.127 & 0.187 & 0.543 \\
\hline & Ventral area 5 & 0.026 & -0.116 & 0.202 & 0.728 \\
\hline & Social organisation (solitary) & 2.967 & 1.097 & 4.553 & 0.008 \\
\hline & Ventral area $2 \times$ social organisation (solitary) & -0.048 & -0.275 & 0.196 & 0.677 \\
\hline & Ventral area $3 \times$ social organisation (solitary) & -0.063 & -0.287 & 0.187 & 0.585 \\
\hline & Ventral area $4 \times$ social organisation (solitary) & -0.239 & -0.443 & 0.016 & 0.041 \\
\hline & Ventral area $5 \times$ social organisation (solitary) & -0.166 & -0.406 & 0.049 & 0.153 \\
\hline
\end{tabular}

Table 6. Relationships between the difference between core body and surface temperature $\left(T_{\text {diff }}\right)$, ventral area (five ventral areas, for details see Fig. 1) and social organisation (solitary vs. social) in seven species of subterranean rodents. 2.5\% HPD and 97.5\% HPD represent lower and upper highest posterior density intervals; pMCMC denotes to the $p$ value obtained from MCMCglmm; ventral area $\times$ social organisation $=$ interaction between ventral area and social organisation.

we divided the venter into five areas (Fig. 1), and for each species, we analysed the pattern of $T_{\text {diff }}$ at $T_{a}$ below, within, and above TNZ (Table 5). Although there were some statistically significant differences in the pattern of $\mathrm{T}_{\text {diff }}$ among these ventral areas for particular species at $\mathrm{T}_{\mathrm{a}} \mathrm{s}$ below and within TNZ (except for B. suillus and G. capensis; see Table 5 and Supplementary Fig. S1), the differences were usually small. Due to this and the absence of any consistent pattern within the tested species, we think that the differences have probably low biological importance. In C. hottentotus and S. cyanus, the differences were found only within TNZ, but not in the lowest $\mathrm{T}_{\mathrm{a}}$. As expected, we found homogeneous pattern of $\mathrm{T}_{\text {diff }}$ at the highest $\mathrm{T}_{\mathrm{a}}$. Together with low values of $\mathrm{T}_{\text {diff }}$ at this $\mathrm{T}_{\mathrm{a}}$, it demonstrates that heat dissipation through the ventral surface is maximal. Similarly, no consistent differences in the pattern of the $\mathrm{T}_{\text {diff }}$ change across the five ventral areas between solitary and social species were detected in either of the three $\mathrm{T}_{\mathrm{a}} \mathrm{s}$ (Table 5).

Nevertheless, limitations of the IRT approach should be considered when measuring $\mathrm{T}_{\mathrm{s}}$ of restricted body areas in small mammals, such as those five ventral areas explored in our study. For instance, the fact that the animals move and bend their bodies during the short recording might provide relatively variable data for such small areas. In this case, the analysis of the insulative quality of the fur might be a better approach to reveal potential differences if such heterogeneity exists. It should be noted that recent findings based on the histological analysis of small skin patches along the body in F. mechowii did not reveal any differences in the amount and structure of the adipose tissue and vascularisation along its venter ${ }^{43}$. This suggests fur having the main role in heat dissipation through the integument in mole-rats and subterranean rodents generally.

For future research on heat dissipation in subterranean rodents, histological analysis of the feet, analysis of $\mathrm{T}_{\mathrm{s}}$ of the only hairless rodent $H$. glaber, experiments based on fur shaving, direct measurement of thermal insulation of fur, and/or measuring of skin temperature with thermocouples could bring valuable information on how subterranean rodents handle heat dissipation which is a crucial aspect for mammals who frequent burrows for their whole lives. 


\section{Data availability}

The datasets generated and analysed during the current study are available from the corresponding author on reasonable request.

Received: 1 February 2020; Accepted: 30 December 2020

Published online: 21 January 2021

\section{References}

1. da Silva, R. G. \& Maia, A. S. C. Principles of Animal Biometeorology Vol. 2 (Springer, Dordrecht, 2012).

2. Mohler, F. S. \& Heath, J. E. Comparison of IR thermography and thermocouple measurement of heat-loss from rabbit pinna. Am. J. Physiol. 254, 389-395 (1988).

3. Phillips, P. K. \& Heath, J. E. An infrared thermographic study of surface temperature in the euthermic woodchuck (Marmota monax). Comp. Biochem. Physiol. A 129, 557-562 (2001).

4. Klir, J. J. \& Heath, J. E. An infrared thermographic study of surface temperature in relation to external thermal stress in three species of foxes: the red fox (Vulpes vulpes), arctic fox (Alopex lagopus), and kit fox (Vulpes macrotis). Physiol. Zool. 65, 1011-1021 (1992).

5. Kuhn, R. \& Meyer, W. Infrared thermography of the body surface in the Eurasian otter Lutra lutra and the giant otter Pteronura brasiliensis. Aquat. Biol. 6, 143-152 (2009).

6. Khamas, W. A., Smodlaka, H., Leach-Robinson, J. \& Palmer, L. Skin histology and its role in heat dissipation in three pinniped species. Acta Vet. Scand. 54, 46 (2012).

7. Johansen, K. Heat exchange through the muskrat tail. Evidence for vasodilator nerves to the skin. Acta Physiol. Scand. 55, 160-169 (1962).

8. Mauck, B., Bilgmann, K., Jones, D. D., Eysel, U. \& Dehnhardt, G. Thermal windows on the trunk of hauled-out seals: hot spots for thermoregulatory evaporation?. J. Exp. Biol. 206, 1727-1738 (2003).

9. Underwood, L. S. \& Reynolds, P. Photoperiod and fur lengths in the Arctic fox (Alopex lagopus L.). Int. J. Biometeorol. 24, 39-48 (1980).

10. Korhonen, H. \& Harri, M. Heat loss of farmed raccoon dogs and blue foxes as evaluated by infrared thermography and body cooling. Comp. Biochem. Physiol. A 84, 361-364 (1986).

11. Reichard, J. D., Prajapati, S. I., Austad, S. N., Keller, C. \& Kunz, T. H. Thermal windows on Brazilian free-tailed bats facilitate thermoregulation during prolonged flight. Integr. Comp. Biol. 50, 358-370 (2010).

12. Gerken, M. Relationships between integumental characteristics and thermoregulation in South American camelids. Animal 4, 1451-1459 (2010).

13. Abdoun, K. A., Samara, E. M., Okab, A. B. \& Al-Haidary, A. A. Regional and circadian variations of sweating rate and body surface temperature in camels (Camelus dromedarius). Anim. Sci. J. 83, 556-561 (2012).

14. Phillips, P. K. \& Heath, J. E. Dependency of surface temperature regulation on body size in terrestrial mammals. J. Therm. Biol. 20, 281-289 (1995).

15. Contreras, L. C. Bioenergetics and distribution of fossorial Spalacopus cyanus (Rodentia): thermal stress, or cost of burrowing. Physiol. Zool. 59, 20-28 (1986).

16. Oufara, S., Barre, H., Rouanet, J. L. \& Chatonnet, J. Adaptation to extreme ambient temperatures in cold-acclimated gerbils and mice. Am. J. Physiol. 253, R39-R45 (1987).

17. Hankenson, F. C., Marx, J. O., Gordon, C. J. \& David, J. M. Effects of rodent thermoregulation on animal models in the research environment. Comp. Med. 68, 425-438 (2018).

18. Hayes, J. P., Speakman, J. R. \& Racey, P. A. The contributions of local heating and reducing exposed surface area to the energetic benefits of huddling by short-tailed field voles (Microtus agrestis). Physiol. Zool. 65, 742-762 (1992).

19. Bustamante, D. M., Nespolo, R. F., Rezende, E. L. \& Bozinovic, F. Dynamic thermal balance in the leaf-eared mouse: the interplay among ambient temperature, body size, and behavior. Physiol. Biochem. Zool. 75, 396-404 (2002).

20. Gilbert, C. et al. One for all and all for one: the energetic benefits of huddling in endotherms. Biol. Rev. 85, 545-569 (2010).

21. Atlee, B. A. et al. The histology of normal llama skin. Vet. Dermatol. 8, 165-176 (1997).

22. McNab, B. K. The metabolism of fossorial rodents: a study of convergence. Ecology 47, 712-733 (1966).

23. Contreras, L. C. \& McNab, B. K. Thermoregulation and energetics in subterranean mammals. Prog. Clin. Biol. Res. 335, 231-250 (1990).

24. Burda, H., Šumbera, R. \& Begall, S. Microclimate in burrows of subterranean rodents: revisited. In Subterranean Rodents (eds Begall, S. et al.) 21-33 (Springer, Berlin, 2007).

25. Šumbera, R. Thermal biology of a strictly subterranean mammalian family, the African mole-rats (Bathyergidae, Rodentia). J. Therm. Biol. 79, 166-189 (2019).

26. Vleck, D. The energy cost of burrowing by the pocket gopher Thomomys bottae. Physiol. Zool. 52, 122-136 (1979).

27. Lovegrove, B. G. The cost of burrowing by the social mole rats (Bathyergidae) Cryptomys damarensis and Heterocephalus glaber: the role of soil moisture. Physiol. Zool. 62, 449-469 (1989).

28. Zelová, J., Šumbera, R., Okrouhlík, J. \& Burda, H. Cost of digging is determined by intrinsic factors rather than by substrate quality in two subterranean rodent species. Physiol. Behav. 99, 54-58 (2010).

29. Luna, F. \& Antinuchi, C. D. Energetics and thermoregulation during digging in the rodent tuco-tuco (Ctenomys talarum). Comp. Biochem. Physiol. A. 146, 559-564 (2007).

30. Sokolov, V. E. Mammal Skin (University of California Press, Berkeley, 1982).

31. Šumbera, R., Zelová, J., Kunc, P., Knížková, I. \& Burda, H. Patterns of surface temperatures in two mole-rats (Bathyergidae) with different social systems as revealed by IR-thermography. Physiol. Behav. 92, 526-532 (2007).

32. Boyles, J. G., Verburgt, L., McKechnie, A. E. \& Bennett, N. C. Heterothermy in two mole-rat species subjected to interacting thermoregulatory challenges. J. Exp. Zool. A Ecol. Genet. Physiol. 317, 73-82 (2012).

33. Vejmělka, F. Charakteristiky srsti podzemních hlodavců ve vztahu k jejich termální biologii. [Fur characteristics of burrowing rodents in relation to their thermal biology. Bc. Thesis, in Czech]. Faculty of Science, University of South Bohemia, České Budějovice, Czech Republic (2016).

34. Cutrera, A. P. \& Antinuchi, C. D. Fur changes in the subterranean rodent Ctenomys talarum: possible thermal compensatory mechanism. Rev. Chil. Hist. Nat. 77, 235-242 (2004).

35. McGowan, N. E., Scantlebury, D. M., Bennett, N. C., Maule, A. G. \& Marks, N. J. Thermoregulatory differences in African mole-rat species from disparate habitats: responses and limitations. J. Therm. Biol. 88, 102495 (2020).

36. Okrouhlík, J., Burda, H., Kunc, P., Knížková, I. \& Šumbera, R. Surprisingly low risk of overheating during digging in two subterranean rodents. Physiol. Behav. 138, 236-241 (2015).

37. Kotze, J., Bennett, N. C. \& Scantlebury, M. The energetics of huddling in two species of mole-rat (Rodentia: Bathyergidae). Physiol. Behav. 93, 215-221 (2008) 
38. Wiedenová, P., Šumbera, R. \& Okrouhlík, J. Social thermoregulation and socio-physiological effect in the subterranean Mashona mole-rat (Fukomys darlingi). J. Therm. Biol. 78, 367-373 (2018).

39. Liwanag, H. E., Berta, A., Costa, D. P., Abney, M. \& Williams, T. M. Morphological and thermal properties of mammalian insulation: the evolution of fur for aquatic living. Biol. J. Linn. Soc. 106, 926-939 (2012).

40. Kasza, I., Hernando, D., Roldán-Alzate, A., Alexander, C. M. \& Reeder, S. B. Thermogenic profiling using magnetic resonance imaging of dermal and other adipose tissues. JCI Insight 1, e87146 (2016).

41. Thigpen, L. W. Histology of the skin of a normally hairless rodent. J. Mammal. 21, 449-456 (1940).

42. Burda, H. Constraints of pregnancy and evolution of sociality in mole-rats with special reference to reproductive and social patterns in Cryptomys hottentotus (Bathyergidae, Rodentia). J. Zool. Syst. Evol. Res. 28, 26-39 (1990).

43. Pleštilová, L. et al. Functional histology of the skin in the subterranean African giant mole-rat: thermal windows are determined solely by pelage characteristics. PeerJ 8, e8883 (2020).

44. Lövy, M., Šklíba, J., Burda, H., Chitaukali, W. N. \& Šumbera, R. Ecological characteristics in habitats of two African mole-rat species with different social systems in an area of sympatry: implications for the mole-rat social evolution. J. Zool. 286, 145-153 (2012).

45. Braude, S. Dispersal and new colony formation in wild naked mole-rats: evidence against inbreeding as the system of mating. Behav. Ecol. 11, 7-12 (2000).

46. Lacey, E. A. \& Wieczorek, J. R. Kinship in colonial tuco-tucos: evidence from group composition and population structure. Behav. Ecol. 15, 988-996 (2004).

47. Lövy, M., Šklíba, J. \& Šumbera, R. Spatial and temporal activity patterns of the free-living giant mole-rat (Fukomys mechowii), the largest social bathyergid. PLoS ONE 8, e55357 (2013).

48. Finn, K. T. Density-dependent effects on body size, philopatry, and dispersal in the damaraland mole-rat (Fukomys damarensis) Master thesis. (Rhodes University, Faculty of Science, Grahamstown, Republic of South Africa. 2017).

49. Zemanová, M., Šumbera, R. \& Okrouhlík, J. Poikilothermic traits in Mashona mole-rat (Fukomys darlingi). Reality or myth?. J. Therm. Biol. 37, 485-489 (2012).

50. Honeycutt, R. Family Bathyergidae (African mole-rats). In Handbook of the Mammals of the World. Lagomorphs and Rodents I Vol. 6 (eds Wilson, D. E. et al.) 352-370 (Lynx Edicions, Barcelona, 2016).

51. Ojeda, A. Family Octodontidae. In Handbook of the Mammals of the World. Lagomorphs and Rodents I Vol. 6 (eds Wilson, D. E. et al.) 536-551 (Lynx Edicions, Barcelona, 2016).

52. Nevo, E., Ivanitskaya, E. \& Beiles, A. Adaptive Radiation of Blind Subterranean Mole Rats (Backhuys Publishers, Kerkwerve, 2001).

53. Hart, J. S. \& Heroux, O. Exercise and temperature regulation in lemmings and rabbits. Can. J. Biochem. Physiol. 33, 428-435 (1955).

54. Cortes, A., Miranda, E., Rosenmann, M. \& Rau, J. R. Thermal biology of the fossorial rodent Ctenomys fulvus from the Atacama desert, northern Chile. J. Therm. Biol. 25, 425-430 (2000).

55. Cortes, A., Tirado, C. \& Rosenmann, M. Energy metabolism and thermoregulation in Chinchilla brevicaudata. J. Therm. Biol. 28, 489-495 (2003).

56. Shido, O., Romanovsky, A., Ungar, A. \& Blatteis, C. Role of intrapreoptic norepinephrine in endotoxin-induced fever in guineapigs. Am. J. Physiol. 265, R1369-R1375 (1993).

57. Chen, P. H. \& White, C. E. Comparison of rectal, microchip transponder, and infrared thermometry techniques for obtaining body temperature in the laboratory rabbit (Oryctolagus cuniculus). J. Am. Assoc. Lab. Anim. Sci. 45, 57-63 (2006).

58. Chapon, P., Bulla, J., Gauthier, A. \& Moussay, S. On the importance of telemetric temperature sensor location during intraperitoneal implantation in rats. Lab. Anim. 48, 114-123 (2014).

59. Vandewint, A. L., Zhu-Pawlowsky, A. J., Kirby, A., Tattersall, G. J. \& Pamenter, M. E. Evaporative cooling and vasodilation mediate thermoregulation in naked mole-rats during normoxia but not hypoxia. J. Therm. Biol. 84, 228-235 (2019).

60. Harrap, M. J. M., de Hempel Ibarra, N., Whitney, H. M. \& Rands, S. A. Reporting of thermography parameters in biology: a systematic review of thermal imaging literature. R. Soc. Open Sci. 5, 181281 (2018).

61. R Core Team. R: a language and environment for statistical computing. R Foundation for Statistical Computing, Vienna, Austria. https://www.R-project.org/ (2016).

62. Muggeo, V. M. R. Segmented: an R package to fit regression models with broken-line relationships. R News 8, $20-25$ (2008).

63. Pinheiro, J., Bates, D., DebRoy, S., Sarkar, D. \& R Core Team. nlme: linear and nonlinear mixed effects models. R package version 3.1-128. CRAN http://CRAN.R-project.org/package=nlme (2016).

64. Lenth, R. Emmeans: estimated marginal means, aka Least-Squares Means. R package version 1.3.4. CRAN https://CRAN.Rproj ect.org/package $=$ emmeans (2019).

65. Hadfield, J. D. MCMC methods for multi-response generalized linear mixed models: the MCMCglmm R package. J. Stat. Softw. 33, 1-22 (2010).

66. Upham, N. S., Esselstyn, J. A. \& Jetz, W. Inferring the mammal tree: Species-level sets of phylogenies for questions in ecology, evolution, and conservation. PLoS Biol. 17, e3000494 (2019).

67. Schliep, K. P. phangorn: phylogenetic analysis in R. Bioinformatics 27, 592-593 (2011).

68. Revell, L. J. phytools: an R package for phylogenetic comparative biology (and other things). Methods Ecol. Evol. 3, 217-223 (2012).

69. de Lamo, D. A., Sanborn, A. F., Carrasco, C. D. \& Scott, D. J. Daily activity and behavioral thermoregulation of the guanaco (Lama guanicoe) in winter. Can. J. Zool. 76, 1388-1393 (1998).

70. Terrien, J., Perret, M. \& Aujard, F. Behavioral thermoregulation in mammals: a review. Front. Biosci. 16, 1428-1444 (2011).

71. Lyman, C. P. Hibernation and Torpor in Mammals and Birds (Academic Press, Cambridge, 1982).

72. Gordon, C. J. Temperature Regulation in Laboratory Rodents (Cambridge University Press, Cambridge, 1993).

73. Shimer, H. W. Adaptations to aquatic, arboreal, fossorial and cursorial habits in mammals III. Fossorial adaptations. Am. Nat. 37, 819-825 (1903).

74. Stein, B. R. Morphology of subterranean rodents. In Life Underground: The Biology of Subterranean Rodents (eds Lacey, E. A. et al.) 19-61 (University of Chicago Press, Chicago, 2000).

75. Thomas, J. R., Shurtleff, D., Schrot, J. \& Ahlers, S. T. Cold-induced perturbation of cutaneous blood flow in the rat tail: a model of nonfreezing cold injury. Microvasc. Res. 47, 166-176 (1994).

76. Daanen, H. A. M. Finger cold-induced vasodilation: a review. Eur. J. Appl. Physiol. 89, 411-426 (2003).

77. Klir, J. J., Heath, J. E. \& Bennani, N. An infrared thermographic study of surface temperature in relation to external thermal stress in the Mongolian gerbil, Meriones unguiculatus. Comp. Biochem. Physiol. A 96, 141-146 (1990).

78. Wunder, B. A. A model for estimating metabolic rate of active or resting mammals. J. Theor. Biol. 49, 345-354 (1975).

79. Šklíba, J., Šumbera, R., Chitaukali, W. N. \& Burda, H. Determinants of daily activity patterns in a free-living Afrotropical solitary subterranean rodent. J. Mammal. 88, 1009-1016 (2007).

80. Šklíba, J. et al. Activity of free-living subterranean blind mole rats Spalax galili (Rodentia: Spalacidae) in an area of supposed sympatric speciation. Biol. J. Linn. Soc. 118, 280-291 (2016).

81. Vlasatá, T. et al. Daily activity patterns in the giant root rat (Tachyoryctes macrocephalus), a fossorial rodent from the Afro-alpine zone of the Bale Mountains Ethiopia. J. Zool. 302, 157-163 (2017).

82. McNab, B. K. The influence of body size on the energetics and distribution of fossorial and burrowing mammals. Ecology 60, $1010-1021$ (1979).

83. Nevo, E. \& Shkolnik, A. Adaptive metabolic variation of chromosome forms in mole rats. Spalax. Exp. 30, 724-726 (1974). 


\section{Acknowledgements}

We thank to K. Hrubá, J. Řihánková, and K. Schoeman for their assistance during data collection and processing and P. Duda for help with phylogenetic analyses. Our thanks are due to R. Pešková for her care of analysed rodents, to prof. C. Pirk for lending us an IRT camera, to prof. A. McKechnie for letting us to use the experimental room, and to two anonymous reviewers for their constructive comments. This study was supported by the Czech Science Foundation (GACR 17-19896S to R.S.), Faculty of Science, University of South Bohemia in České Budějovice (Junior Premium Scholarship for talented applicants to F.V.), South Bohemia university Grant (GAJU No. 048/2019/P to F.V.), and South African Research Chair (SARChI chair, GUN Number 64756 to N.C.B.; Chair Postdoctoral Fellowship to J.O.).

\section{Author contributions}

R.S., F.V., J.O., and M.L. conceived and designed the conceptual framework of the study. F.V., M.L., and J.O. collected data. F.V., M. L., G.S. and J.O. analysed data. E.N. and N.C.B. contributed with experimental animals. R.S. and N.C.B. provided funding for research. F.V and R.S. wrote the text with assistance of all co-authors.

\section{Competing interests}

The authors declare no competing interests.

\section{Additional information}

Supplementary Information The online version contains supplementary material available at https://doi. org/10.1038/s41598-021-81404-3.

Correspondence and requests for materials should be addressed to R. ̌́.

Reprints and permissions information is available at www.nature.com/reprints.

Publisher's note Springer Nature remains neutral with regard to jurisdictional claims in published maps and institutional affiliations.

(c) (i) Open Access This article is licensed under a Creative Commons Attribution 4.0 International License, which permits use, sharing, adaptation, distribution and reproduction in any medium or format, as long as you give appropriate credit to the original author(s) and the source, provide a link to the Creative Commons licence, and indicate if changes were made. The images or other third party material in this article are included in the article's Creative Commons licence, unless indicated otherwise in a credit line to the material. If material is not included in the article's Creative Commons licence and your intended use is not permitted by statutory regulation or exceeds the permitted use, you will need to obtain permission directly from the copyright holder. To view a copy of this licence, visit http://creativecommons.org/licenses/by/4.0/.

(C) The Author(s) 2021 